\title{
The Lifespan Trajectory of the Encoding-Retrieval Flip: A Multimodal Examination of Medial Parietal Cortex Contributions to Episodic Memory
}

\author{
- Inge K. Amlien, ${ }^{1}{ }^{-}$Markus H. Sneve, ${ }^{1}$ Didac Vidal-Piñeiro, ${ }^{1}$ Kristine B. Walhovd, ${ }^{1,2}$ and Anders M. Fjell ${ }^{1,2}$ \\ ${ }^{1}$ Centre for Lifespan Changes in Brain and Cognition, University of Oslo, 0317 Oslo, Norway, and ${ }^{2}$ Department of Radiology and Nuclear Medicine, Oslo \\ University Hospital, 0372 Oslo, Norway
}

The formation of episodic memories is associated with deactivation during encoding and activation during retrieval in the posteromedial cortex (PMC). We hypothesized that the encoding/retrieval (E/R) flip is a critical component of episodic memory across the lifespan because structural and metabolic changes in the PMC coincide with the fine tuning of the episodic memory system in development and the reductions of memory performance in aging. The aims of the present study were, first, to describe lifespan trajectories of PMC encoding and retrieval activity in 270 human participants ( 167 females) from 6 to 80 years of age. Our second goal was to construct a model for episodic memory development in which contributions from brain activity, cortical thickness (CT), and structural connectivity are accounted for. We found that modulation of neural activity in response to memory encoding and retrieval demands was not fully developed until adolescence and decreased from adulthood through old age. The magnitude of the $E / R$ flip was related to source memory and $55 \%$ of the age-related variance in source memory performance during childhood and adolescence could be accounted for by the E/R flip, CT, and mean diffusivity together. However, only CT and the E/R flip provided unique contributions with which to explain memory performance. The results suggest that neural dynamics in the PMC is related to the development of episodic memory during childhood and adolescence. The similar trajectories of the $\mathrm{E} / \mathrm{R}$ flip and episodic memory emergence and decline through development and aging further suggests that a lifelong relationship exists.

Key words: development; E/R flip; episodic memory; fMRI; lifespan; posteromedial cortex

Significance Statement

Modulation of neural activity in the posteromedial cortex (PMC) in response to memory encoding/retrieval (E/R) demands (E/R flip) does not reach its peak until adolescence and decreases from adulthood through old age. The magnitude of the $\mathrm{E} / \mathrm{R}$ flip is related to source memory and $55 \%$ of the age-related variance in source memory performance during childhood and adolescence can be accounted for by the E/R flip and brain structure together. The results suggest that neural dynamics in the PMC is related to the development of episodic memory function during childhood and adolescence and the similar trajectories of the E/R flip and episodic memory performance through development and aging suggests that a lifelong relationship exists.

\section{Introduction}

The posteromedial cortex (PMC) deactivates during successful episodic memory encoding (Daselaar et al., 2004) and activates during successful retrieval (Wagner et al., 2005; Daselaar et al.,

Received June 19, 2017; revised June 21, 2018; accepted June 23, 2018.

Author contributions: I.K.A. wrote the first draft of the paper; I.K.A., M.H.S., D.V.-P., K.B.W., and A.M.F. designed research; I.K.A., M.H.S., and D.V.-P. performed research; I.K.A., M.H.S., D.V.-P., K.B.W., and A.M.F. analyzed data; I.K.A., M.H.S., D.V.-P., K.B.W., and A.M.F. wrote the paper.

This work was supported by the European Research Council's Starting Grant Scheme (Grants 283634 and 725025 to A.M.F. and Grant 313440 to K.B.W.), the Norwegian Research Council, and the Department of Psychology, University of 0sIo. Data processing was performed on the TSD (Tjeneste for Sensitive Data) facilities owned by the University of Oslo and operated and developed by the TSD service group at the University of Oslo, Information Technology Department (USIT).

The authors declare no competing financial interests. 2009a). This reversal of functional response is likely critical for memory and has been dubbed the encoding/retrieval (E/R) flip (Vannini et al., 2011; Huijbers et al., 2012; 2013; Gilmore et al., 2015). Interestingly, the PMC is among the regions that undergo the most rapid structural (Brown and Jernigan, 2012; Tamnes et al., 2013; Amlien et al., 2016) and metabolic (Blüml et al., 2013; Degnan et al., 2014) changes during late childhood and adolescence, coinciding with episodic memory development (Ofen et al., 2007; Ghetti and Bunge, 2012). An intriguing question is

Correspondence should be addressed to Inge K Amlien, Dept of Psychology, Centre for Lifespan Changes in Brain and Cognition, University of 0slo, Pb. 1094 Blindern, 0317 0slo, Norway. E-mail: inge.amlien@psykologi.uio.no. DOI:10.1523/JNEUROSCI.1702-17.2018

Copyright $\odot 2018$ the authors $\quad 0270-6474 / 18 / 388666-14 \$ 15.00 / 0$ 
whether improvement in the ability to dynamically regulate PMC activity during encoding and retrieval can account for developmental gains in memory. The aims of the present study were first to test lifespan trajectories of PMC encoding and retrieval activity and then to construct a model for episodic memory development in which the contributions from brain activity patterns, cortical thickness (CT), and structural connectivity are accounted for.

PMC encoding deactivation and retrieval activation for remembered items was first reported $>15$ years ago (Otten and Rugg, 2001; Wagner and Davachi, 2001; Lundstrom et al., 2003; Daselaar et al., 2004; Wagner et al., 2005; Daselaar et al., 2009a; Duarte et al., 2010; for review, see Kim, 2011, 2013). Studies examining the E/R flip directly are few (Vannini et al., 2011; Huijbers et al., 2012; Gilmore et al., 2015) and we are aware of one study examining the E/R flip in aging (Vannini et al., 2013) showing that the magnitude of functional modulation in PMC declines with age and is related to memory performance.

Although the role of the PMC in memory and the mechanisms behind the E/R flip are not fully understood, the function of the PMC is often linked to the default mode network (DMN). The DMN may support mental processes that are inwardly oriented and occur spontaneously during rest. The network deactivates when attention is directed toward external stimuli or during an active task (Raichle et al., 2001; Buckner et al., 2008). Deactivation of PMC during encoding may thus be interpreted as a result of attending to external stimuli and actively encoding information. Conversely, increased retrieval activation may reflect the process of orienting toward internal representations of stored memories. The DMN has been identified in infants (Gao et al., 2009), but the organization of functional connectivity in the brain still undergoes changes during development (Supekar et al., 2009; Power et al., 2010). Deactivation of the PMC during episodic memory encoding is less pronounced in children than in adults. However, it is unknown whether the lack of disengagement reflects reduced functional modulation or if children show the same range of modulation between encoding and retrieval as adults, with less deactivation but increased activation during retrieval (Chai et al., 2014).

In the present study, we tested patterns of functional modulation of activity in the PMC between encoding and retrieval of episodic memories during development and aging in participants from 6 to 80 years of age. We hypothesized a protracted development of modulation of PMC activity evidenced by an increased $\mathrm{E} / \mathrm{R}$ flip, with subsequent reductions in aging, causing children and older adults to show similar PMC activity patterns. Further, we hypothesized that CT and structural connectivity would both be related to the magnitude of the E/R flip and source memory performance in childhood and adolescence and that a multimodal model would explain a substantial amount of the agerelated variance in source memory development. An extended sample (participants 6-80 years of age) was used to describe the lifespan trajectories of the E/R flip and address the question of whether the pattern seen in children mirrors the reductions reported in aging, whereas the multimodal analyses were restricted to the developmental subsample with complete multimodal data (participants 6-30 years of age).

\section{Materials and Methods}

\section{Participants}

The full sample included in the analyses counted 270 participants from 6 to 80 years of age. The participant pool consisted of newly recruited participants, as well as participants recruited from existing studies coordinated from the Center for Lifespan Changes in Brain and Cognition
(LCBC) at the Department of Psychology, University of Oslo, Norway [The Norwegian Mother and Child Cohort Neurocognitive Study (MOBA)/ Neurocognitive Development/ Cognition and Plasticity Through the Lifespan]. The research project was approved by the Regional Ethical Committee of South Norway and all participants $>12$ years of age gave written informed consent; participants $<12$ years of age gave oral informed consent to participate in the study. For all participants $<18$ years of age, written informed consent was also obtained from their guardians. The participants had no history of neurological or psychiatric disorders, chronic illness, learning disabilities, or use of medicines known to affect nervous system functioning. They were also righthanded, spoke Norwegian fluently, and had normal or corrected to normal hearing and vision. All participants were rewarded for their participation with cash or gift cards and the 13 participants recruited through the MOBA study were also rewarded with gifts (toys). A total of 340 participants were considered for inclusion in the study. Thirty-eight participants were selected for a delayed memory test and were thus excluded from the full sample. Eleven participants were excluded because of various problems during MR acquisition leading to invalid or unanalyzable data (relative movement during fMRI exceeding $1.5 \mathrm{~mm}$, missing trials, sound problems during task, operator error during scan, etc.); 15 were excluded because they remembered $<10 \%$ of the items with source memory or had $>50 \%$ false alarms or misses; 5 participants were excluded for neuroactive medication or alcohol intake; and 1 participant was excluded because of incidental MR findings on the radiological examination. After exclusions, the developmental subsample consisted of 105 participants eligible for fMRI analyses, with ages ranging from 6 to 30 years ( $M=19.45, S D=5.72,61$ females), of which 90 participants had the full set of data and were included in the multimodal and structural equation modeling analyses. The sample of healthy older participants consisted of 165 participants $30-80$ years of age $(\mathrm{M}=55.80, \mathrm{SD}=12.27$, 106 females). The full sample entered in the analyses thus consisted of 270 participants $(\mathrm{M}=41.66, \mathrm{SD}=20.48$, females $=167)$ who had undergone the complete MR-scanning procedure. Task fMRI data from 72 of the young and 143 of the older participants have previously been used in studies with nonoverlapping research questions (Sneve et al., 2015; Vidal-Piñeiro et al., 2017).

\section{Memory task and procedure}

The participants were scanned using fMRI during both encoding and retrieval while performing an incidental memory task (Sneve et al., 2015). The stimulus material for the memory task consisted of 100 line drawings depicting common objects, accompanied by one of two questions asking if the participants could either lift or eat the object. The item-question combinations were locked in such a fashion that all objects had one specific question associated with it. For example, the drawing of a wheelchair always had the question "Can you eat it?" associated with it. During the encoding phase, two runs with 50 objects each were presented for the participants. Each run started with a period of $11 \mathrm{~s}$ recording baseline activity, during which a fixation cross was presented. This baseline activity recording was also repeated in the middle and at the end of each run. Every encoding trial started with a recorded female voice asking the participant the Norwegian equivalent of one of two questions: "Can you lift it?" or "Can you eat it?" One second after the question onset, a line drawing appeared on screen. The participant responded to the question by pressing a button with the index finger on either the left or right response grip according to the instructions on the screen. The hand used to produce a "yes" response was counterbalanced between participants. After a response window of $2 \mathrm{~s}$, the line drawing was replaced by a fixation cross that remained on screen during the interstimulus interval, which varied randomly between 1 and $7 \mathrm{~s}$ with an exponential distribution over 4 discrete intervals (mean duration $2.98 \mathrm{~s}, \mathrm{SD}=2.49 \mathrm{~s}$ ). The jittering of stimulus onsets facilitated later disentangling of fMRI data reflecting different encoding conditions (Ollinger et al., 2001; Serences, 2004).

When the encoding session was over, the participants were taken out of the scanner and were seated in a waiting area for $\sim 1 \mathrm{~h}$ until the next scan session. The participants were not explicitly instructed to remember the stimuli and were not informed of the memory test until just before 
the first test trial. The test runs were also performed during fMRI in the same scanner. Test trials started with the prerecorded female voice asking (question 1): "Have you seen this before?" A picture of the item then appeared on screen and the participant responded by pressing the response grip button corresponding to "yes" or "no." If the participant responded "no" or did not respond within $2 \mathrm{~s}$, the current trial was aborted and the experiment continued with the next trial. If the participant answered "yes (I have seen this item before)," then a follow-up question was presented (question 2): "Do you remember what you were supposed to do with it?" Again, if the participant answered "no," then the current trial was aborted and the experiment proceeded with the next trial. If the participant answered that (s)he remembered what (s)he was supposed to do with the item, then a follow-up question was presented (question 3): "What were you supposed to do with it?" Here, the participant was given a two-alternative forced choice between the actions presented during the encoding phase. For statistical analyses, test trial responses were classified as follows: (1) recognition (correct "yes" response to question 1), (2) source memory (correct "yes" response to question 1 and 2 and correct response to question 3), or (3) miss (incorrect "no" response to question 1). Note that the specific questions asked during scanning were simplified to fit within the temporal limits of the paradigm, but all participants were instructed in detail before the test session that the questions pertained to the item-action evaluation performed at encoding.

All visual stimuli ( $\sim 10$ visual degrees in diameter) were presented on an NNL 32-inch LCD Monitor at a resolution of $1920 \times 1080$ pixels (Nordic NeuroLab) positioned $176 \mathrm{~cm}$ from the mirror attached to the coil. Participants responded using the ResponseGrip system (Nordic NeuroLab) and were shown a response feedback indicator on the screen. Auditory stimuli were presented to the participants through headphones.

\section{MRI data acquisition}

fMRI. A 3T Siemens Skyra system with a 24-channel Siemens head coil was used to acquire all MR images during the memory task. Two fMRI runs were acquired during encoding and four were acquired during retrieval, all with the same parameters: 43 transversally oriented gapless slices were recorded using a BOLD-sensitive $\mathrm{T} 2^{*}$-weighted echo planar image (EPI) sequence (repetition time $(\mathrm{TR})=2390 \mathrm{~ms}$, echo time $(\mathrm{TE})=30 \mathrm{~ms}$, flip angle $=90^{\circ}$, voxel size $=3 \times 3 \times 3 \mathrm{~mm}$, field of view $($ FOV $)=224 \times 224 \mathrm{~mm}$, interleaved acquisition (GRAPPA acceleration factor $=2$ ). Three dummy volumes were collected at the start of each run to avoid T1 saturation effects in the analyzed data. Each encoding run consisted of 131 volumes, whereas the length of the retrieval runs varied dependent on the participants' responses because negative answers to any of the first two questions ended the trial. A standard double-echo gradient-echo field map sequence was acquired for distortion correction of the EPI images.

Diffusion tensor imaging (DTI). A single-shot twice-refocused spinecho echo planar imaging (EPI) with 64 directions was acquired with the following parameters: $\mathrm{TR}=9300 \mathrm{~ms}$, $\mathrm{TE}=87 \mathrm{~ms}$, b-value $=1000$ $\mathrm{s} / \mathrm{mm}^{2}$, voxel size $=2.0 \times 2.0 \times 2.0 \mathrm{~mm}$, slice spacing $=2.6 \mathrm{~mm}, \mathrm{FOV}=$ 256 , matrix size $=128 \times 130 \times 70,1$ non-diffusion-weighted $(b=0)$ image. To correct for eddy-current-induced image distortions, 1 b0weighted image was acquired with the reverse phase encoding, but otherwise identical acquisition parameters. These images were obtained on the same $3 \mathrm{~T}$ magnet as the fMRI images. The participants recruited through MOBA already had recorded DTI scans with 32 directions acquired on a $1.5 \mathrm{~T}$ Siemens Avanto scanner using a 12-channel head coil with the following parameters: $\mathrm{TR}=8200 \mathrm{~ms}$, TE $=81 \mathrm{~ms}$, b-value $=$ $700 \mathrm{~s} / \mathrm{mm}^{2,}$ voxel size $=2.0 \times 2.0 \times 2.0 \mathrm{~mm}$, field of view $=128$, matrix size $=128 \times 128 \times 64$, number of b0 images $=5$, GRAPPA acceleration factor $=2$. One adolescent and four adults did not have adequate DTI images and were thus excluded from the DTI analyses.

sMRI. One sagittal T1-weighted MPRAGE volume consisting of 176 sagittally oriented slices was obtained using a turbo field echo pulse sequence $\left(\mathrm{TR}=2300 \mathrm{~ms}, \mathrm{TE}=2.98 \mathrm{~ms}\right.$, flip angle $=8^{\circ}$, voxel size $=1 \times$ $1 \times 1 \mathrm{~mm}, \mathrm{FOV}=256 \times 256 \mathrm{~mm})$. For the youngest children, the integrated parallel acquisition technique was used, acquiring multiple T1 scans within a short scan time, enabling us to discard scans with residual

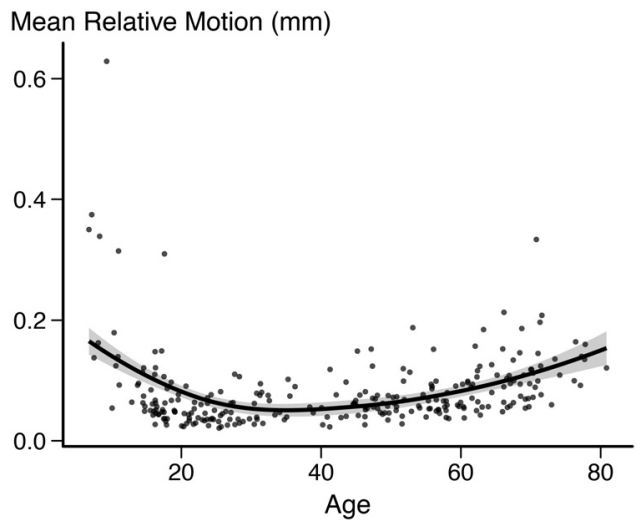

Figure 1. Estimated relative motion across all runs for all included participants. Fit line used R's LOESS function with 1.3 span and SE is marked as a shaded area.

movement and to average the scans with sufficient quality. Previous studies have shown that accelerated imaging does not introduce measurement bias in surface-based measures when using FreeSurfer for image analysis compared with a standard MPRAGE protocol with otherwise identical voxel dimensions and sequence parameters (Wonderlick et al., 2009), which is consistent with our own analyses.

Several other MRI volumes were recorded during the session and were not related to the current experiment, including sequences intended for and examined by a radiologist to rule out and medically follow up on any neuroradiological findings in the sample. Total scanning times were $\sim 58$ min for the encoding session and $45 \mathrm{~min}$ for the retrieval session, depending on the participants' responses. The youngest children in the MOBA sample spent less time in the scanner during the encoding $(\sim 25$ min) and retrieval ( $\sim 45 \mathrm{~min})$ fMRI tasks because the non-task based MRI sequences were recorded in a separate session. The DTI images for these eight participants were collected on average $100.62 \mathrm{~d}$ in advance of the fMRI session.

\section{Image analysis}

fMRI preprocessing. Preprocessing of the functional image data was performed using a combination of the FreeSurfer 5.3 Functional Analysis Stream tools (http://freesurfer.net/fswiki/FsFast) and components from the FSL toolbox (http://fsl.fmrib.ox.ac.uk/fsl/). All functional images were first corrected for distortions caused by b0 inhomogeneities in EPI scans (FSL PRELUDE/FUGUE; http://fsl.fmrib.ox.ac.uk/fsl) before the images were motion corrected, slice timing corrected to the middle of a volume's TR, intensity normalized, and registered to the same participants' anatomical volumes using FSL's fMRI Expert Analysis Tools (FEAT).

Because children and elderly participants, both of whom typically exhibit more head motion during scanning, were included in the study, care was taken to address head motion. Relative framewise displacement estimated by MCFLIRT averaged across all included participants and runs was $0.081 \mathrm{~mm}$. The motion distribution followed a U-shaped trajectory relative to age, with the expected pattern of increased relative motion at the extremes of the age range (Figure 1).

We used a machine learning approach, FMRIB's ICA-based $\mathrm{X}$-noiseifier (FIX), to clean motion-related noise and other artifacts from the fMRI data using a trained multilevel hierarchical classifier (Griffanti et al., 2014; Salimi-Khorshidi et al., 2014). This approach consists of several steps. First, the preprocessed data were decomposed into multiple components using MELODIC (Beckmann and Smith, 2004). We then manually classified the components for a subset of the participants (16) and labeled each component as signal or noise. A set of $>180$ temporal and spatial features was extracted and the classifier (an ensemble learning classifier combining $\mathrm{k}-\mathrm{NN}$, decision trees, and support vector machines) was trained on the manually labeled dataset. This enabling learning of the relevant spatial and temporal features needed for building a robust model. We tested the performance of the model on our training data by performing leave-one-out accuracy tests with varying thresholds 
Table 1. FIX performance

\begin{tabular}{lllllllll}
\hline Threshold & 1 & 2 & $\mathbf{5}$ & 10 & 20 & 30 & 40 & 50 \\
\hline True positive (signal) & 98.5 & 98.5 & $\mathbf{9 7}$ & 95.6 & 94.2 & 90.7 & 88.9 & 87.8 \\
True negative (noise) & 39.3 & 47.6 & $\mathbf{5 7 . 3}$ & 66.5 & 75.6 & 79.4 & 82.8 & 87.6 \\
\hline
\end{tabular}

Classification accuracy over a range of thresholds was tested using the training set consisting of 16 participants. The chosen threshold 5 is shown in bold.

(Table 1). We set the threshold at a conservative 5, where 10 out of the 16 participants in the training set had $100 \%$ true positive rate in the leaveone-out tests. When we examined the discrepancies between the manually labeled components and the components automatically labeled by FIX, we found discrepancies only in the high numbered ICA components, meaning that the discrepancies were present only in components explaining miniscule amounts of the variance in the data. The classifier was applied on the complete dataset with the selected threshold and the noise components ( $40 \%$ average) were regressed from the preprocessed data in addition to 24 motion confound regressors (high-pass filtered at $100 \mathrm{~s})$.

Before further fMRI analyses commenced, the 4D functional datasets were resampled to a common template ("fsaverage") using the surfacebased interparticipant registrations created during the previous cortical reconstruction.

fMRI analyses. A first-level general linear model (GLM) was set up for each run consisting of three main regressors of interest during encoding (source memory, recognition, miss) plus one regressor of no interest (trials without a response) and five main regressors of interest during retrieval (source memory, recognition, miss, correct rejection, false alarm) plus three regressors of no interest (no response to question 1, no response to question 2, no response to question 3). The regressors were modeled as events with onsets and durations corresponding to the item presentation period ( $2 \mathrm{~s}$ ) and convolved with a two-gamma canonical hemodynamic response function. In addition to the task regressors and their temporal derivatives, estimated motion correction parameters and a set of polynomials (up to the second degree) were included in the GLM as nuisance regressors. The model and the data were processed through a high-pass filter with a cutoff at $0.01 \mathrm{~Hz}$. Temporal autocorrelations in the residuals were corrected using a prewhitening approach.

Parameter estimates for the contrast between fMRI activity of items that were subsequently remembered with full source information versus implicit baseline fMRI activity and full source memory versus misses were calculated for each participant and brought to the group level for both activity during encoding and during retrieval. Statistical significance was tested at each vertex on the cortical surface using GLMs and a weighted least-squares approach, treating participants as random effects and weighting them by the inverse of their first-level noise variance (Thirion et al., 2007). Group statistical maps were FDR corrected at $p<0.05$.

Defining the E/R flip ROI. The E/R flip has been defined as the conjunction between successful $\mathrm{E} / \mathrm{R}$ activity contrasted with baseline activity (Vannini et al., 2013), but has also been defined by contrasting memory success with misses, so-called difference memory (DM) (Daselaar et al., 2009b). The different approaches may lead to different regions being identified as ROIs, so we explored both approaches. To identify the overlap between areas that deactivate during successful encoding and activate during successful retrieval, we performed conjunction analyses (Nichols et al., 2005) for the source memory versus baseline contrast, first using the young adults only (18-30 years, $n=55)$ and then the complete development sample ( $6-30$ years, $n=115)$ and for the complete lifespan sample ( $6-80$ years, $n=270)$. We repeated the analyses for the source memory vs miss (DM) contrast using the young adults group. The statistical estimates for the contrasts were false discovery rate (FDR) corrected at $p \leq 0.05$. Conjunction analyses were then performed on the resulting statistical maps, resulting in maps including only the vertices that were both significantly deactivated (compared with baseline or compared with miss in the DM contrast) during encoding and activated during retrieval; that is, areas displaying an encoding retrieval flip.

The ROIs defined using both the baseline and DM approaches were created using the young adults and were found to be restricted to the medial PMC. These ROIs were used as masks in further analyses. We extracted the average encoding and retrieval parameter estimates for all conditions separately [source memory, recognition, misses, correct rejections (retrieval only), false alarms (retrieval only)] for all participants. In addition to the surface-based analyses, average signal during encoding and retrieval was also extracted from the left and right hippocampi automatically segmented by FreeSurfer at the individual level (Fischl et al., 2002).

DTI preprocessing. The b0 images were also collected with reversedphase encode blips, resulting in pairs of images with distortions going in opposite directions. From these pairs, we estimated the susceptibilityinduced off-resonance field using a method similar to what is described in Andersson et al. (2003) as implemented in FSL (Smith et al., 2004). We then applied the estimate of the susceptibility induced off-resonance field with the eddy tool (Andersson and Sotiropoulos, 2016), which was also used to correct eddy-current-induced distortions and subject head movement, and aligned all images to the first image in the series. Finally, we rotated the bvecs in accordance with the image alignments performed in the previous steps (Jenkinson et al., 2002; Leemans and Jones, 2009).

DTI analyses. To analyze the structural connectivity of the PMC, we used tract based spatial statistics (TBSS) available under FSL. First, the preprocessed, eddy current, movement, and susceptibility fieldcorrected data were used as the input to the standard TBSS processing stream (FSL; http://www.fmrib.ox.ac.uk/fsl). A tensor model was first to the preprocessed diffusion data using FDT. The data was then aligned into a common space before the mean FA image was created and thinned to create a mean alignment-invariant skeleton, which represents the centers of all tracts common to the group (Rueckert et al., 1999; Smith, 2002; Smith et al., 2004; 2006; Andersson and Jenkinson, 2007; Andersson et al., 2007). We then projected the fractional anisotropy (FA) and mean diffusivity (MD) data for each individual onto this skeleton and performed whole-brain voxelwise analyses on the FA and MD values and the interaction term between age and source memory. Permutation-based nonparametric cluster inference ("Randomize," a part of the FSL software suite) was used, controlling for scanner, sex, age, and source memory. Sex was included as a covariate of no interest in the analyses because sex differences in white matter (WM) microstructure have been reported (Inano et al., 2011; Kanaan et al., 2012; Rathee et al., 2016). Five thousand permutations were performed and the results were corrected for multiple comparisons across space by threshold-free cluster enhancement (Smith and Nichols, 2009; Winkler et al., 2014). The threshold level for a significant difference was set at $p<0.05$ (corrected). Because we have also previously observed larger age differences in PMC in this age span for MD compared with FA (Tamnes et al., 2010) and we found no significant effects of FA after statistical corrections were performed, MD was chosen as the DTI measure of interest. We thus collected the average MD values from the regions of the TBSS skeleton displaying a significant age-source memory interaction and saved the residuals after regressing on scanner type and estimated movement. This corrected measure was entered as the DTI measure in the multimodal analyses.

The rationale for adding the microstructural measure was to investigate whether structural connectivity measures added to the contributions of the PMC E/R flip in explaining age differences in source memory. We used a data-driven approach for defining the DTI ROI. We believe that this approach, unbiased by anatomical constraints, is consistent with keeping consistency across analyses and modalities through the study. Although the regions that emerged as structural ROIs did not directly overlap with the PMC ROI, this does not exclude that a relationship between the regions exists and variations in, for example, WM microstructure in regions different from where one finds the $\mathrm{E} / \mathrm{R}$ flip could be relevant for episodic memory.

sMRI preprocessing. FreeSurfer 5.3 was used for the cortical and volumetric reconstruction of the T1-weighted structural data (http:// freesurfer.net). The processing steps include motion correction and averaging (Reuter et al., 2010), removal of non-brain tissue (Ségonne et al., 2004), automated Talairach transformation, and intensity correction (Sled et al., 1998). Intensity and continuity information from the 3D volume are used in segmentation and deformation procedures to reconstruct a gray/WM and gray/CSF boundary throughout the brain (Dale et 
al., 1999; Fischl et al., 2002; 2004b). Cortical surfaces then undergo inflation, registration to a spherical atlas, and identification of gyral and sulcal regions (Fischl et al., 2004a; Desikan et al., 2006). Subcortical WM and deep gray matter volumetric structures were segmented, yielding volumetric measurements of the hippocampi (Fischl et al., 2002). Although there have been concerns that the hippocampal volume estimations from FreeSurfer differ from manual segmentations (Wenger et al., 2014), associations between FreeSurfer estimated volumes and manually estimated volumes are satisfactory (Schoemaker et al., 2016) and intracranial volume (ICV)-adjusted age trajectories are nearly identical (Schmidt et al., 2018). An experienced operator manually inspected individual surfaces and segmentations for accuracy. Minor corrections were needed for eight participants mainly due to suboptimal skull strip leading to inaccurate pial surfaces, including manual edits of the brain mask for six participants, and adding intensity normalization control points for two participants.

sMRI analyses. Thickness maps were smoothed at FWHM $15 \mathrm{~mm}$ before analyses. We assessed the interaction between age and source memory on CT with FreeSurfer's mri_glmfit using a GLM approach, controlling for the effect of sex and the linear age and source memory terms. We also tested for main effects of source memory on CT, controlling for sex. We did include sex as a covariate in the ROI analyses because sex is associated with differences in brain structure (Raznahan et al., 2011); however, studies using FreeSurfer do rarely detect sex differences in mean CT or trajectories of CT development (Fjell et al., 2009; Tamnes et al., 2010; Amlien et al., 2016). The analyses were performed across all vertices and the results were thresholded using pre-cached Monte Carlo simulation with a cluster-forming-threshold of $p<0.01$ and and Bonferroni adjusted for analyses across both hemispheres. Average CT of all vertices overlapping with the age-source memory interaction cluster was used as the CT measure in the following analyses. We thus consider CT to be a marker for structural development in this age range. The interpretation of CT- in ROI-based analyses does also arguably make more neuroanatomical sense than surface area and CT/BOLD activity correlations have also been reported elsewhere (Rasser et al., 2005; Hegarty et al., 2012; Joshi et al., 2016). We thus chose to use CT measures in the following analyses.

\section{Statistical analyses}

Polynomial regression analyses were performed to examine the continuous relationship between behavior data (source memory, recognition, misses, false alarms, and $d^{\prime}$ ) and age. Similar analyses were performed on the E/R flip and signal was extracted from the PMC during encoding and retrieval separately and for left and right hippocampi, both for encoding and retrieval BOLD activity and for ICV corrected residuals of hippocampus volume. ICV was calculated by use of an atlas normalization procedure described by Buckner et al. (2004).

To examine how much of the variance in source memory the combined multimodal measures were able to explain, source memory, age, $\mathrm{E} / \mathrm{R}$ flip, $\mathrm{MD}$, and CT were entered in a path analysis based on structural equation modeling (Amos, version 22). We wanted to test the hypothesis that source memory performance differences are mediated through a greater range of activity in the PMC region during encoding and retrieval, which in turn is dependent on structural brain maturation. We also repeated the structural equation modeling, where we replaced the E/R flip variable and instead entered both the PMC encoding and retrieval variables separately. Direct and indirect effects were calculated. Indirect effects are calculated as the product of the partial path weights from the predictor variable to the indicator variable through other variables in the model. Indirect effects were only calculated for significant paths. Browne and Cudeck (1992) suggested that a root mean square error of approximation (RMSEA) $<0.08$ is indicative of a reasonable error of approximation and that a RMSEA $<0.05$ would indicate a close fit and models with values $>0.1$ should not be used. We therefore used the moderately conservative threshold of RMSEA $<0.05$ for determining adequate model fit.

Finally, we estimated the proportion of age-related variance in source memory shared with E/R flip, MD, and CT using the following formula: $\frac{r_{A-C}^{2}-r_{A-C \cdot B k}^{2}}{r_{A-C}^{2}}$, where each kth brain marker $(\mathrm{B} k)$ was partialled from
Table 2. Demographics and behavior performance

\begin{tabular}{lccc}
\hline & Sample & & \\
\cline { 2 - 4 } & Development & Aging & Total \\
\hline$N$ (female/male) & $105(61 / 44)$ & $165(106 / 59)$ & $270(167 / 103)$ \\
Mean age (range) & $19.4(6.8-30.4)$ & $55.8(30.8-80.8)$ & $41.66(6.8-80.8)$ \\
Source memory & $53.2 \%(16.4)$ & $49.7 \%(13.8)$ & $51.1 \%(14.9)$ \\
Recognition & $75.7 \%(11.1)$ & $74.1 \%(10.6)$ & $74.7 \%(10.8)$ \\
Misses & $21.3 \%(10.7)$ & $22.4 \%(10.2)$ & $21.7 \%(10.4)$ \\
False alarms & $4.5 \%(5.8)$ & $6.4 \%(4.5)$ & $5.7 \%(5.1)$ \\
$d^{\prime}$ & $2.58(0.61)$ & $2.27(0.52)$ & $2.39(0.57)$ \\
\hline
\end{tabular}

Demographics and memory performance scores for the development sample (left), the aging sample (middle), and the total sample (right) are shown. Range is shown for age; SD is shown in the parentheses for the memory performance measures. The $d^{\prime}$ measure was derived from recognition and false alarms.

the correlation between age (A) and source memory (C) (Hedden et al., 2016). To estimate the proportion of unique age-related variance shared with each brain marker (B), we computed partial correlation analyses using the following formula: $\frac{r_{A-C \cdot B \in ! k}^{2}-r_{A-C \cdot B \in k}^{2}}{r_{A-C}^{2}}$, where $\mathrm{B} \in k$ is the set of all brain markers (E/R flip, CT, and MD) and $\mathrm{B} \epsilon ! k$ is all brain markers excluding the $k$ th marker. This procedure was repeated with encoding and retrieval activity entered separately.

\section{Results}

\section{Behavioral results}

Demographics and task performance on the memory retrieval task performed during fMRI are presented in Table 2.

Plots of behavior measures tested against age are shown in Figure 2. Source memory performance was related to age with the age trajectory forming an inverted $U$-shaped function. The cubic regression was significant $\left(R^{2 \mathrm{adj}}=0.135, F_{(3,266)}=14.97, p<\right.$ $0.001, y=0.215+0.0264 x-5.62 \times 10^{-4} x^{2}+3.28 \times 10^{-6}$ $\left.x^{3}\right)$ and significantly better than the linear and quadratic models. Recognition was also related to age forming an inverted $\mathrm{U}$-shaped function and the quadratic regression was significant $\left(R^{2 \mathrm{adj}}=0.037 F_{(2,267)}=6.109, p=0.003, y=0.695+4.24 \times\right.$ $\left.10^{-3} x-5.77 \times 10^{-6} x^{2}\right)$ and also significantly better than the linear model. The number of recognition misses was not significantly related to age regardless of whether a linear, quadratic, or cubic model was used (linear model, $R^{2 \text { adj }}<0.000, F_{(1,268)}=$ $\left.0.938, p=0.334, y=0.205+2.99 \times 10^{-4} x\right)$. The number of false alarms was related to age and the cubic regression was significant $\left(R^{2 \text { adj }}=0.071, F_{(3,266)}=7.899, p<0.001\right.$, $y=0.0998-5.36 \times 10^{-3} x+1.39 \times 10^{-4} x^{2}-9.62 \times$ $\left.10^{-7} x^{3}\right)$, with a U-shaped function and a decrease toward the end of the age-range. The cubic model was significantly better than both the linear and quadratic models. $d^{\prime}$ was significantly related to age with an inverted U-shaped function and the quadratic regression model was significant $\left(R^{2 \mathrm{adj}}=0.123, F_{(2,267)}=19.87\right.$, $\left.p<0.001, y=2.47+0.0104 x-2.35 \times 10^{-4} x^{2}\right)$ and significantly better than the linear model.

\section{fMRI results}

Identification of the encoding-retrieval flip

Only the vertices showing both significant (FDR-corrected) deactivation during successful source memory encoding and activation during retrieval compared with baseline were classified as flipping voxels in the conjunction analysis. This is a stricter criterion than contrasting encoding deactivations with retrieval activations alone. We initially defined the E/R flip using the young adult group alone. The rationale for this was that, if the children, as hypothesized, showed either reduced encoding deactivations or reduced retrieval activations, then we would risk not being able to identify a region displaying the $\mathrm{E} / \mathrm{R}$ flip. The conjunction anal- 


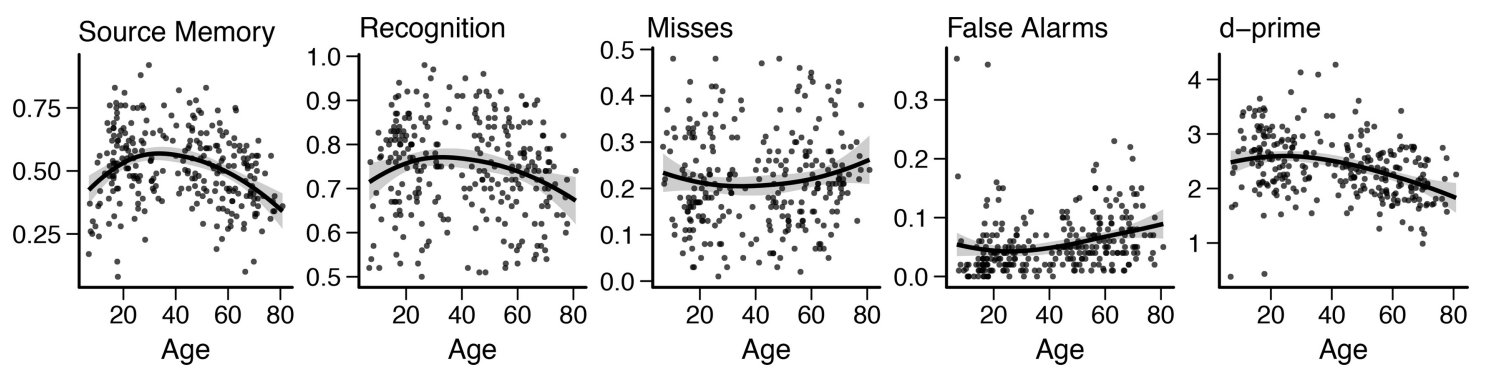

Figure 2. Scatterplots showing the relationships between age and (left to right): Source memory, recognition memory, recognition misses, false alarms, and $d^{\prime}$ score, from 6 to 80 years. Fit line used R's LOESS function with 1.3 span and SE is marked as a shaded area.
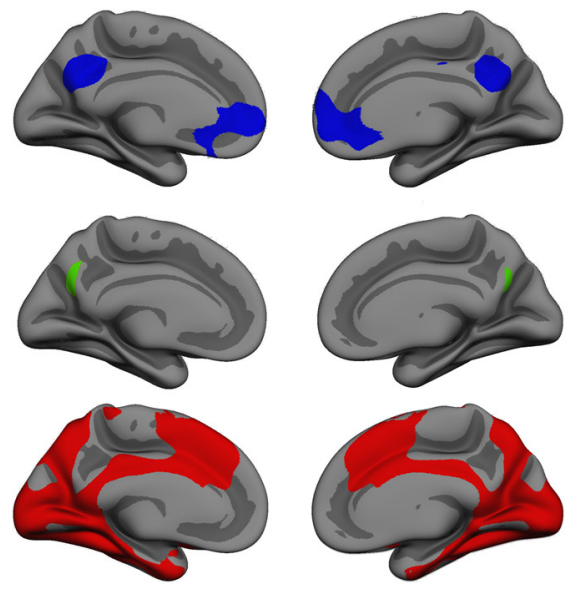

Encoding Deactivation

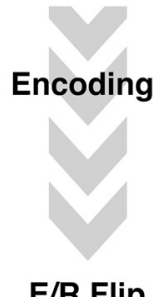

E/R Flip

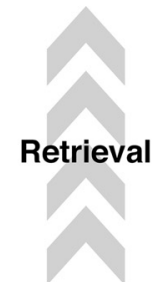

E/R FLIP
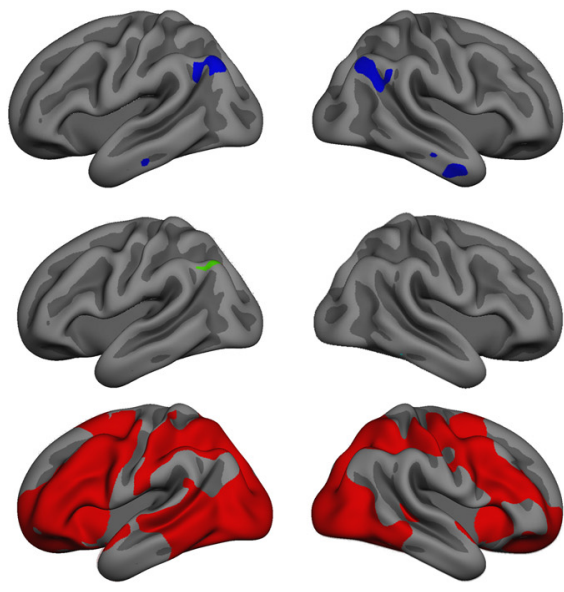

Retrieval Activation

Figure 3. Conjunction analysis results based on 55 young adult participants (18.6-30.4 years of age). Top row, Blue areas are significantly deactivated during successful source memory encoding. Bottom row, red areas are significantly activated during successful source memory retrieval. Middle row: Green areas represent the area of overlap: the E/R Flip. Significant areas are FDR corrected at $p<0.05$.

ysis was performed based on group statistical maps, resulting in a map of vertices significantly deactivated during source memory encoding and significantly activated during source memory retrieval (Fig. 3). The conjunction analysis left us with three regions where the E/R flip was evident, namely a cluster in the PMC bilaterally and a posterior lateral parietal region in the left hemisphere only. The activity pattern that we discovered in the posterior ventral parietal region is a region that has previously been shown to exhibit the same E/R flip pattern also found in PMC (Daselaar et al., 2009a; Gilmore et al., 2015). The PMC was defined as the ROI a priori based on previous studies (Huijbers et al., 2012; 2013; Vannini et al., 2013; Gilmore et al., 2015), so we created labels of the overlap between PCM encoding deactivation and retrieval activation in the two hemispheres separately and subjected these ROIs to further analyses. Individual parameter estimates were extracted from the contrast between source memory and baseline both for encoding and retrieval. The mean signal from the left and right PMC was extracted for both sessions and the E/R flip was defined as the resulting difference between encoding and retrieval parameter estimates averaged across left and right PMC. Maps of significant activation or deactivation during encoding or retrieval are presented in Figure 4.

\section{E/R flip and source memory}

$\mathrm{E} / \mathrm{R}$ flip activity was related to source memory performance, the linear regression equation was significant $\left(R^{2 \text { adj }}=0.016\right.$,
$\left.F_{(1,268)}=5.407, p=0.021\right)$, and the relationship between E/R flip and source memory was positive.

\section{$E / R$ flip and age}

E/R flip activity was related to age and the cubic regression was significant $\left(R^{2 \mathrm{adj}}=0.074, F_{(3,266)}=8.166, p<0.001\right.$, $y=0.0926+0.012 x-3.16 \times 10^{-4} x^{2}+2.18 \times 10^{-6}$ $\left.x^{3}\right)$ and the model fit of the cubic regression was trending toward fitting significantly better than the quadratic and linear models (Sig F change $=0.059$ ). To determine how the age effects of the E/R flip were driven by age-related encoding and retrieval activity patterns, we performed additional regression analyses on the subcomponents of the E/R flip measure. E/R flip ROI activity during encoding was related to age and the cubic regression was significant $\left(R^{2 \text { adj }}=0.051, F_{(3,266)}=5.789, p<0.001\right.$, $\left.y=0.135-0.017 x+4.06 \times 10^{-4} x^{2}-2.93 \times 10^{-6} x^{3}\right)$. The model fit of the cubic regression was significantly better than the quadratic and linear models. E/R flip ROI activity during retrieval was also related to age, but here only the linear regression was significant $\left(R^{2 \text { adj }}=0.028, F_{(1,268)}=8.632, p=0.004\right.$, $y=0.18-0.00103 x)$.

E/R flip fMRI activity was characterized by a pattern that was mirrored between development and aging (Fig. 5), with increases in E/R flip until adolescence and monotonous reductions until old age. The magnitude of the reductions through age was such 


\section{Encoding}
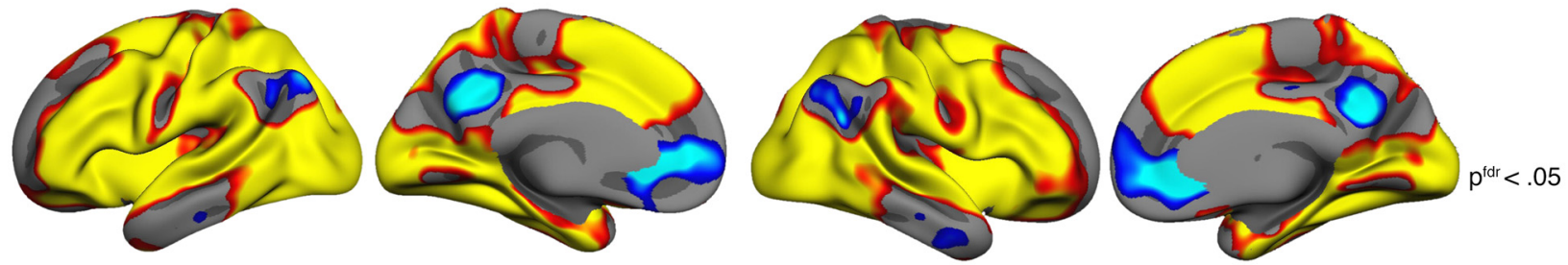

Retrieval
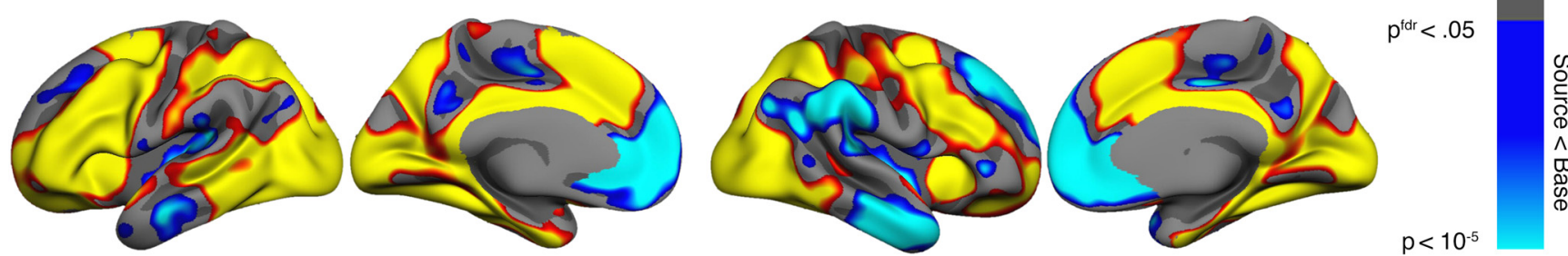

Figure 4. Areas showing significant source memory success activation contrasted with baseline are shown in warm colors and deactivations in cool colors during encoding (top) and retrieval (bottom). Only vertices significant after FDR correction at the $p<0.05$ level are shown.
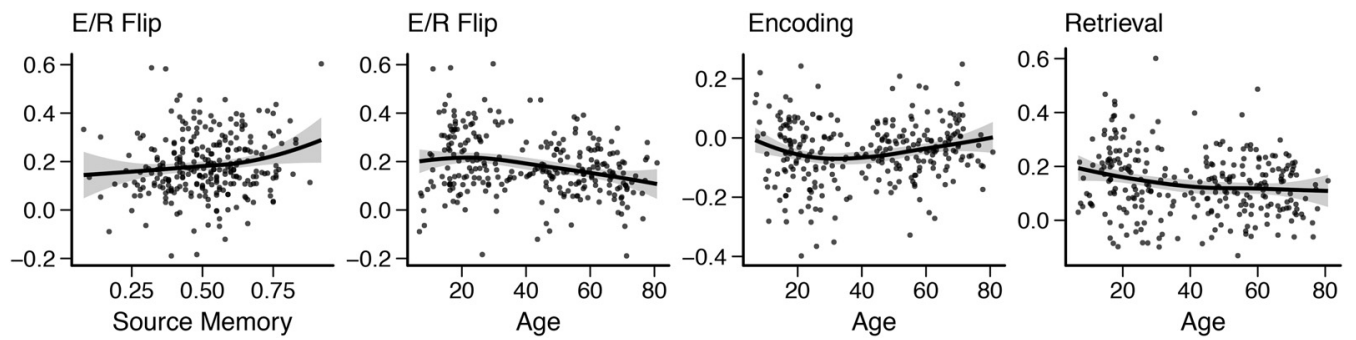

Figure 5. Left to right, E/R flip by source memory, E/R flip by age, encoding activity in the E/R flip ROI by age, retrieval activity in the E/R flip ROI by age. Fit line used R's LOESS function with 1.3 span and SE is marked as a shaded area.
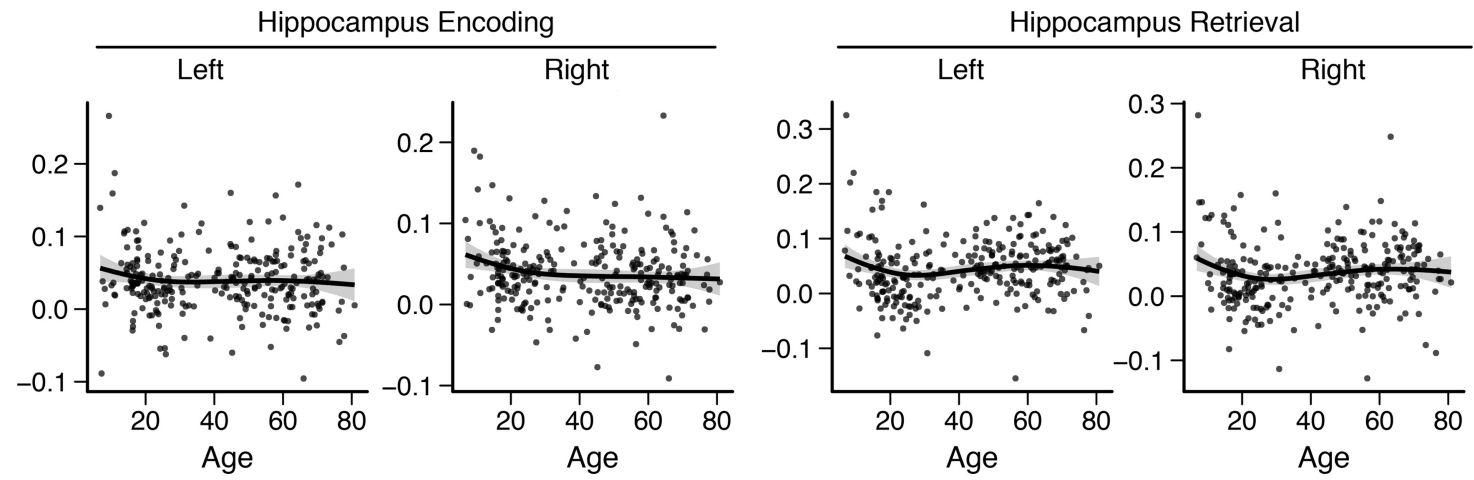

Figure 6. Hippocampus BOLD activity (parameter estimates) during encoding and retrieval. Fit line used R's LOESS function with 1.3 span and SE is marked as a shaded area.

that the 70-to 80-year-olds showed E/R flip and encoding activity almost at the level of the children.

\section{Hippocampus age trajectories}

Supplementary regression analyses were performed on the BOLD signal in bilateral hippocampus and age (Fig. 6). Activity in the right hippocampus during recall was positively related to retrieval success and the cubic regression was significant $\left(R^{2 \text { adj }}=\right.$ $0.031, F_{(3,266)}=3.86, p=0.010, y=0.803+0.8 x-2.761$ $\left.x^{2}+2.071 x^{3}\right)$. Hippocampus activity during both encoding and retrieval was significantly related to age. For encoding, the cubic regression was significant for right hippocampus $\left(R^{2 \text { adj }}=\right.$ $0.031, F_{(3,266)}=3.874, p=0.009, y=0.104-0.00511$ $\left.x+0.000115 x^{2}-8.05 \times 10^{-7} x^{3}\right)$ and, for retrieval, left $\left(R^{\text {2adj }}=0.012, F_{(3,266)}=13.43, p<0.001, y=0.204-\right.$ $\left.0.0155 x+0.000394 x^{2}-2.92 \times 10^{-6} x^{3}\right)$ and right hippocampus $\left(R^{2 \text { adj }}=0.010, F_{(3,266)}=11.5, p<0.001\right.$, $\left.y=0.175-0.0133 x+0.000334 x^{2}-2.45 \times 10^{-6} x^{3}\right)$. The model fit of the cubic regressions was significantly better than the quadratic and linear models. The shape of the regression function showed a slight initial decrease with little change through middle age before another dip in old age.

Hippocampus volume (ICV residuals) followed an inverted $\mathrm{U}$ trajectory through the lifespan (Fig. 7) and the quadratic regression was significant (left: $R^{2 \text { adj }}=0.27, F_{(2,252)}=47.74, p<$ 
Hippocampus Volume
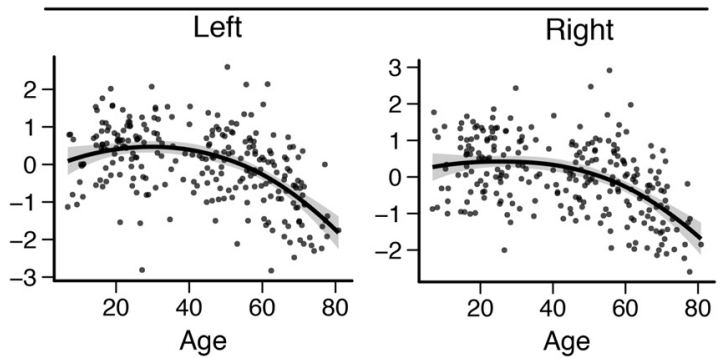

Figure 7. Hippocampus volume lifespan trajectories for bilateral hippocampi. Fit line used R's LOESS function with 1.3 span and SE is marked as a shaded area.

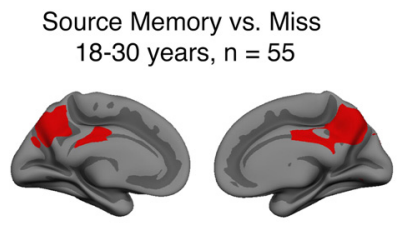

Source Memory vs. Baseline 18-30 years, $n=55$

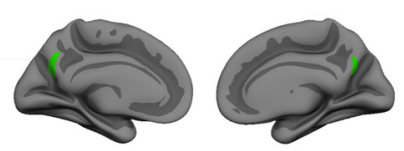

Source Memory vs. Baseline $6-30$ years, $n=115$
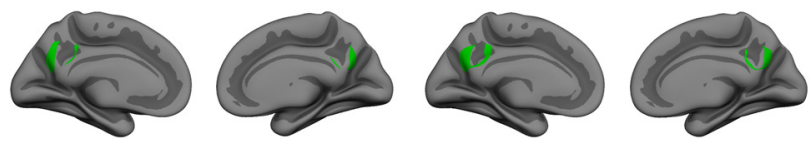

Figure 8. Comparison of different approaches used for defining the E/R flip. Top left, ER/Flip ROI defined using the DM contrast in the young adult sample. Middle left, E/R flip ROI defined using the baseline contrast in the young adult sample (ROl used in the main analyses). Top right, Scatterplot showing individual data points extracted from the E/R flip ROI defined using the DM approach. The black line is fitted to the $E / R$ flip defined using the DM approach, whereas the green lines posted for reference represent the $E / R$ flip defined using the baseline approach. Lines are fitted using $R$ (ggplot2, LOESS span $=1.3$ ). Bottom row, E/R flip ROl defined using different samples. Bottom left, Complete development sample ( $6-30$ years of age, $n=105)$. Bottom right: Complete lifespan sample ( $6-80$ years of age, $n=270$ ).

$0.001, y=-0.322+0.0543 x-0.000893 x^{2} ;$ right: $R^{2 \mathrm{adj}}=$ $0.24, F_{(2,252)}=40.2, p<0.001, y=-0.101+0.0406$ $\left.x-0.000729 x^{2}\right)$. ICV-corrected hippocampus volumes (residuals) were significantly related to source memory (left: $R^{2}=$ $0.042, p<0.001$; right: $R^{2}=0.027, p=0.009$ ), but when corrected for the linear and quadratic age terms, the relationship was not significant (left: $p=0.655$; right: $p=0.998$ ). Both the fMRI and volumetric results are consistent with earlier reports on lifespan changes in hippocampus volume and activity (Van Petten, 2004; Ostby et al., 2009; Walhovd et al., 2011; Wierenga et al., 2014a).

\section{Alternative E/R flip ROI}

We tested different approaches for defining the E/R flip ROI. First, we generated the E/R flip ROIs using a DM approach (contrasting source memory with misses). The resulting ROIs are shown in Figure 8 (top left). Consistent with previous literature, we found that the ROIs extended spatially over a larger area than the implicit baseline approach (Fig. 8, middle left). The spatially
Source Memory x Age (CT)
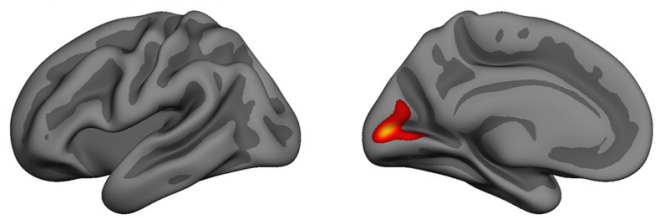

\section{Source Memory (CT)}
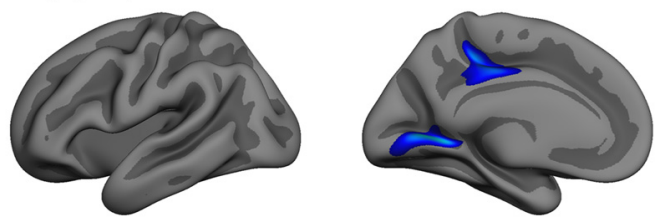

Figure 9. Multiple-comparisons-corrected results showing clusters with a significant source memory-CT relation (top) and source memory-age interactions (bottom). Analyses are based on the developmental subsample with complete multimodal data.

more restricted E/R flip ROI defined using the baseline contrast was almost completely overlapped by the DM ROI. Comparing lifespan trajectories of the E/R flip based on the two different strategies (Fig. 8, top right), we found that they yielded similar overall patterns, but with a longer apparent increase in E/R flip magnitude with the larger, DM-based ROI. Baseline versus DM approaches are discussed in-depth in a review article by Gilmore et al. (2015), who define the E/R flip as "a regional BOLD response pattern in which the direction of evoked activity, relative to resting baseline, flips between encoding and retrieval." Following Gilmore et al. (2015), the baseline defined ROI was used for all other analyses.

Further, as alternatives to define the E/R flip ROI based on the young adults only, we ran additional analyses defining the $E / R$ flip ROI using both the full development sample (6-30 years of age, $n=105)$ and the complete lifespan sample $(6-80$ years of age, $n=270$ ). The resulting ROIs can be seen in Figure 8 (bottom row). The main findings were progressively larger ROIs as we increased sample size and age range in both directions. Although this pattern can be influenced by different activity patterns in development and aging, differences in statistical power between analyses may also affect the size of the ROIs.

Given that the ROI based on the young adults included almost only vertices common to the ROIs defined based on the alternative samples and our hypothesis that the ability to modulate activity in the PMC is not yet fully developed in children and may be reduced in aging, further analyses were based on the ROI defined in the young adults sample (18-30 years of age).

\section{Multimodal development model}

To quantify the influence of E/R flip and brain structure on memory development, we constructed a model containing structural measures relevant to memory development in addition to age, source memory, and E/R flip. We extracted CT and MD measures from the brain regions showing significant interaction with age; that is, the regions where the relationship between the brain measures and source memory were not constant across age.

$C T$

CT was extracted from a posterior cluster that remained significant after correcting for multiple comparisons, encompassing cuneus and calcarine sulcus (Fig. 9, top). The interaction was positive, meaning that the source memory-CT relationship increased with age. Thickness in this ROI correlated negatively with 
Table 3. Correlation matrix

\begin{tabular}{lrcccccc}
\hline Age & -0.026 & & & & & & \\
Source memory & 0.064 & $\mathbf{0 . 3 2 8}$ & & & & & \\
Recognition $d^{\prime}$ & 0.120 & 0.106 & $\mathbf{0 . 5 7 3}$ & & & & \\
PMCE/R flip & -0.077 & 0.207 & $\mathbf{0 . 2 9 6}$ & $\mathbf{0 . 4 0 9}$ & & & \\
MD & 0.088 & -0.153 & -0.097 & -0.141 & -0.172 & & \\
CT & -0.113 & $-\mathbf{0 . 4 4 6}$ & $\mathbf{- 0 . 2 6 2}$ & -0.018 & $\mathbf{- 0 . 2 1 9}$ & 0.129 & \\
Motion & -0.095 & $\mathbf{- 0 . 5 9 9}$ & $\mathbf{- 0 . 4 3 5}$ & $\mathbf{- 0 . 2 3 4}$ & $\mathbf{- 0 . 2 2 2}$ & $\mathbf{- 0 . 3 4 4}$ & $\mathbf{- 0 . 3 3 1}$ \\
& Sex & Age & Srcmem & $d^{\prime}$ & E/R flip & MD & CT \\
\hline
\end{tabular}

Pearson correlation matrix. Significant correlations are shown in bold $(p<0.05)$. Sex is coded with female $=1$, male $=2$. Data are from the developmental subsample with complete multimodal data ( $n=90,6-30$ years).
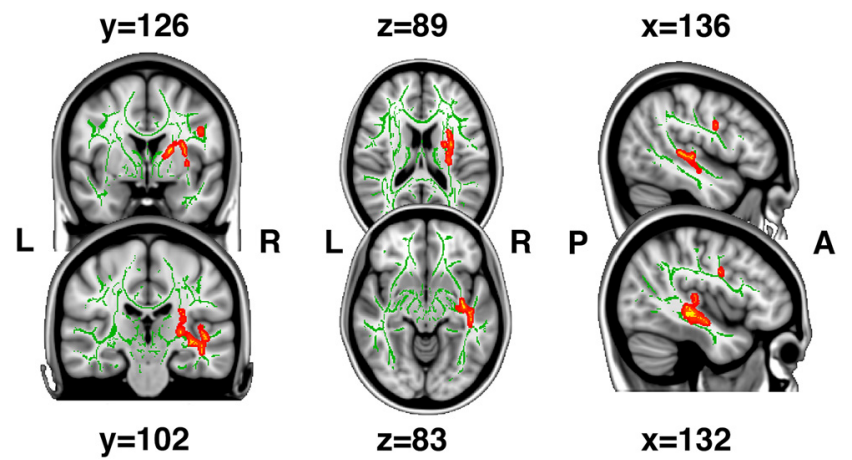

Figure 10. Threshold-free cluster enhancement-corrected $(p<0.05)$ results showing voxels where the source memory-MD relationship differs with age. Effects are filled for readability using tbss_fill. Analyses are based on the developmental subsample with complete multimodal data.

Table 4. Partial correlations

\begin{tabular}{|c|c|c|c|c|c|}
\hline Bk & $A-C$ & $A-C \bullet B k$ & $A-C \bullet B I ̂ ! k$ & Shared \% & Unique $\%$ \\
\hline FLIP & 0.33 & 0.29 & 0.24 & $24.5 \%$ & $8.1 \%$ \\
\hline MD & 0.33 & 0.32 & 0.22 & $6.0 \%$ & $0.4 \%$ \\
\hline CT & 0.33 & 0.24 & 0.28 & $44.7 \%$ & $28.9 \%$ \\
\hline All brain markers ( $B \in k$ ) & 0.33 & 0.22 & & $55.0 \%$ & \\
\hline
\end{tabular}

Correlations and partial correlations among age $(A)$, source memory $(C)$, and brain markers $B k$, where Bîk is the set of all brain markers (E/R flip, MD, and CT) and Bî!k is all brain markers excluding the kth marker. Shared \% is the percentage of variance in the age-source memory relationship that is shared with the brain marker. Unique $\%$ is the percentage of variance in the age-source memory relationship that is uniquely accounted for when all other brain markers have been partialled out.

age $(r=-0.45, p<0.001)$, source memory $(r=-0.26, p=$ $0.013)$, and E/R flip $(r=-0.22, p=0.038)$ in the developmental subsample (Table 3 ). As background information, we also tested the effect of source memory on CT vertexwise across the cortical surfaces. A main effect of source memory on CT was found in two left hemisphere clusters when controlling for the effect of sex, one cluster encompassing lingual gyrus, and one cluster on the border of precuneus, isthmus cingulate, and posterior cingulate cortex (Fig. 9, bottom).

\section{Mean diffusivity}

MD was extracted from a region in the left medial temporal lobe, left longitudinal fasciculus, and corticospinal tract, where the age-source memory interaction analysis revealed increased source memory-MD relation with age (Fig. 10). MD did not correlate significantly with any other variable of interest in the developmental subsample (Table 3 ) and there were no main effects of source memory on MD that remained significant after correcting for multiple comparisons.

To estimate the proportion of age variance in source memory that could be accounted for by the individual brain measures, a series of partial correlations were conducted (Table 4). E/R flip,
$\mathrm{MD}$, and CT together accounted for $55.0 \%$ of the age-related variance in source memory performance. Of this, $8.1 \%$ of the age-related variance in source memory was uniquely accounted for by the E/R flip, $0.4 \%$ by $\mathrm{MD}$, and $28.9 \%$ by CT, whereas the rest was accounted for by more than one of the measures together. E/R flip shared $24.5 \%$ of its age-related variance with the other measures, MD 6.0\%, and CT 44.7\%. An identical analysis with the PMC encoding and retrieval variables entered separately as in structural equation model $\mathrm{C}$ resulted in an overall reduction in the age-related variance in source memory $(26.6 \%)$ that we were able to account for. Part of the reduction could likely be explained by variance suppression effects on the age-source memory relationship by $\mathrm{E} / \mathrm{R}$ activation, indicated by negative shared variance (encoding: $-15.2 \%$, retrieval: $-11.3 \%$ ).

Aiming to separate the age-related variance in source memory that could be explained by each of the functional and structural measures (Fig. 11), we performed path analyses (Fig. 12). Age was entered as the only exogenous variable, source memory was the endogenous variable, and $\mathrm{E} / \mathrm{R}$ flip, $\mathrm{MD}$, and CT were entered as mediating variables. Directional paths were drawn from age to all other variables, to source memory from all other variables, and to E/R flip from all other variables except source memory. We revised the initial model (Fig. 12A) in iterations, trimming the arrow with lowest critical ratio until only significant relationships $(p<0.05)$ remained. In the final model (Fig. 12B), source memory was related to age $(\beta=0.28,95 \% \mathrm{CI}: 0.068 \sim 0.494)$ and $\mathrm{E} / \mathrm{R}$ flip $(\beta=0.24,95 \% \mathrm{CI}: 0.030 \sim 0.459)$. CT was also related to age $(\beta=-0.45,95 \%$ CI: $-0.604 \sim-0.252)$ and $\mathrm{E} / \mathrm{R}$ flip $(\beta=$ $-0.22,95 \%$ CI: $-0.412 \sim-0.012)$. Age exerted a small indirect effect on source memory through CT and E/R flip ( $\beta=0.024$, $95 \%$ CI: $0.002 \sim 0.086$ ). The final model yielded a satisfactory fit to the data with a RMSEA value of 0.048 (PCLOSE $=0.376$, relative $\left.\chi^{2}=1.21, \mathrm{CFI}=0.989, \mathrm{NFI}=0.943\right)$.

Finally, we created a structural equation model in which, instead of the E/R flip variable, we entered both PMC encoding and retrieval variables separately, with arrows from age to all variables, from MD and CT to all other variables but age, and from PMC encoding and retrieval to source memory, with an additional arrow from PMC encoding to PMC retrieval. Using identical procedures for model trimming as for the E/R flip analyses, the final model (Fig. 12C) showed that retrieval activity is most directly related to source memory and encoding activity was indirectly related to source memory through its relationship with retrieval. Age was directly related to source memory $(\beta=0.32$, 95\% CI: $0.107 \sim 0.505)$, encoding $(\beta=-0.22$, 95\% CI: $-0.414 \sim-0.007)$, and CT $(\beta=-0.45,95 \%$ CI: $-0.604 \sim$ $-0.252)$ and there were small indirect effects of age on source memory through the $\mathrm{E} / \mathrm{R}$ path $(\beta=-0.03)$ and through the CT-retrieval path $(\beta=-0.03)$. Encoding was directly related to retrieval $(\beta=0.41,95 \% \mathrm{CI}: 0.217 \sim 0.557)$ and indirectly to source memory through retrieval $(\beta=0.15,95 \%$ CI: $0.060 \sim$ $0.259)$. CT was directly related to retrieval $(\beta=-0.20,95 \% \mathrm{CI}$ : $-0.372 \sim-0.010)$ and indirectly to source memory through retrieval $(\beta=-0.075,95 \% \mathrm{CI}:-0.174 \sim-0.011)$. The final iteration of this model did also provide a good fit to the data with an RMSEA value of 0 (PCLOSE $=0.969$, relative $\chi^{2}=0.266$, $\mathrm{CFI}=1, \mathrm{NFI}=0.99)$.

\section{Discussion}

The ability to recall episodic memories is dependent on the dynamic range of neural activity in the PMC and the interplay between neural processes occurring during encoding and retrieval (Daselaar et al., 2009a; Vannini et al., 2011; Huijbers et al., 2012, 

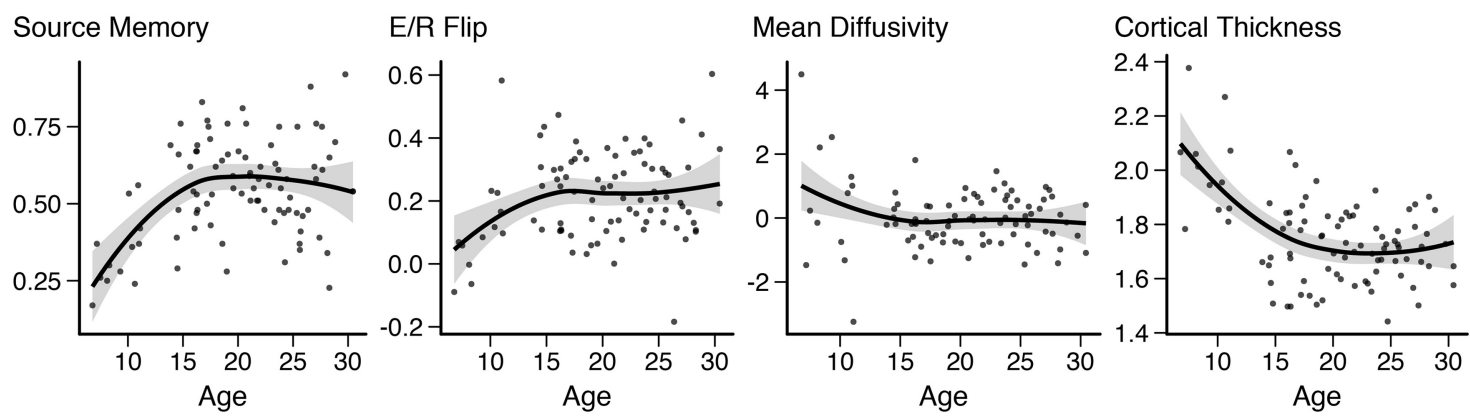

Figure 11. Scatterplots showing the data entered in the structural equation model for source memory development from 6-30 years of age. Left to right, Source memory, E/R flip, MD, and CT. Lines are fitted to the data using R's LOESS function with 1.3 span and SE is marked as a shaded area.
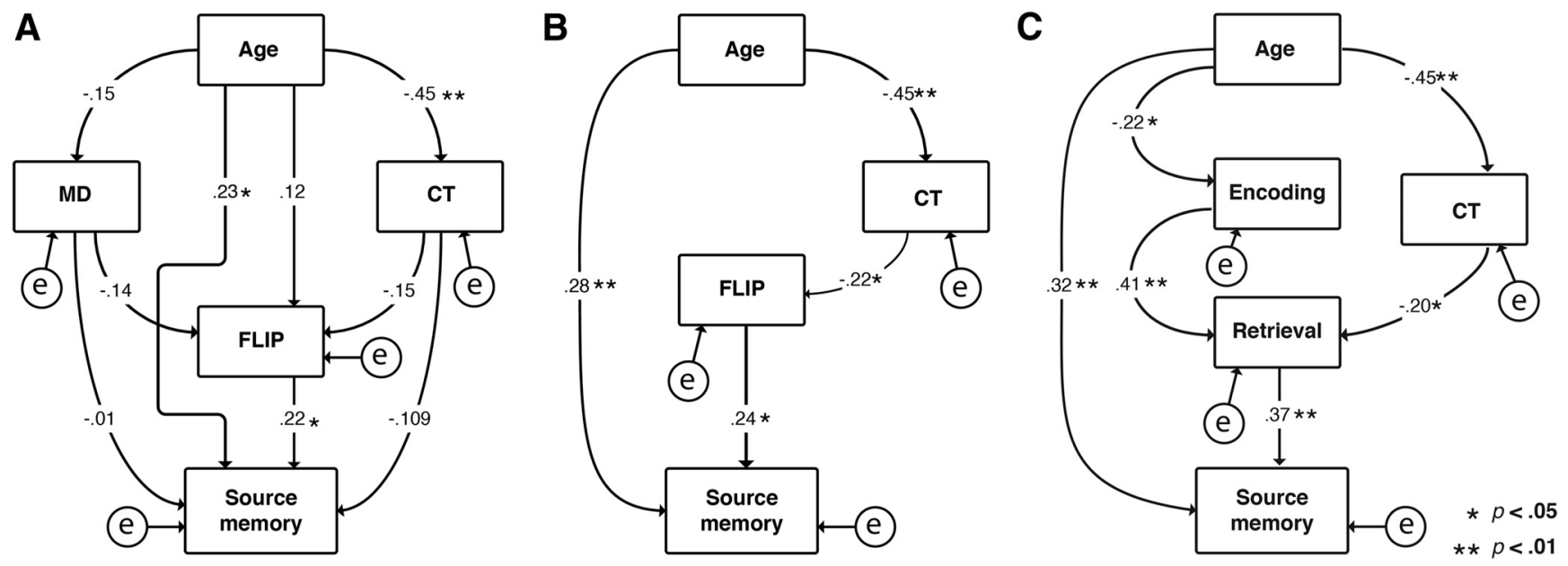

Figure 12. Structural equation models. $\boldsymbol{A}$, Initial model. $\boldsymbol{B}$, Final model. , Final model with encoding and retrieval entered separately. Numbers on paths represent standardized partial regression weights. Analyses are based on the developmental subsample with complete multimodal data.

2013). Here, we demonstrate that efficient functional modulation of the PMC is not yet fully developed in preadolescent children. The combination of age, E/R flip, CT, and MD explained $17 \%$ of the variance in source memory performance, but $>50 \%$ of the age-related performance differences. These age-related differences indicate that the functional development of the PMC and related brain regions is important for the emergence of the ability to encode and recollect episodic memories.

Young adults and adolescents deactivated the PMC during successful source memory encoding, but this deactivation was absent in children. The lack of deactivations in children is consistent with Chai et al. (2014), who reported less encoding-related deactivation in posterior parietal DMN in children compared with older participants. The deactivations already seen in adolescents indicate that emergence of the ability to modulate PMC activity during memory operations is likely a central feature of brain development ongoing at this age.

Activity in the PMC shares many similarities with the rest of the DMN and deactivations may reflect attention orientated outward; that is, attending to external stimuli in the encoding task (Huijbers et al., 2012). Deactivation of the DMN during encoding, possibly to allocate cognitive resources to task-oriented processes, is associated with better subsequent memory performance (Kim, 2011). Activation of the DMN occurs when attention is oriented inwards toward one's own mental processes and is associated with successful retrieval of episodic memories (Kim et al., 2010). Likely, the ability of the PMC to dynamically toggle between deactivation and activation is important to the develop- ment of source memory in addition to activation/deactivation strength alone. An intriguing question is whether the neural processes occurring in the PMC during encoding and retrieval reflect fundamentally different tasks served by the same cortical area, which are seen as bipolar activation patterns, or if they reflect varying intensity of a unitary task or process.

\section{E/R flip through the lifespan}

Reductions in E/R flip have been demonstrated in aging (Vannini et al., 2013) and we add to this by showing the E/R flip trajectory through the lifespan. E/R flip trajectory steeply rose with age until early adulthood before it declined monotonously through the rest of life. The encoding deactivations in the PMC seemed to follow a similar pattern, but peaking later. The 70- to 80 -year-old participants displayed similar levels of encoding deactivations as children. Although it is tempting to assume that age-related differences in development (apparent increase) and aging (apparent decrease) reflect similar mechanisms, we do not know what causes the differences in BOLD responses with age. We need targeted studies focusing on the exact cognitive and neural mechanisms underlying PMC activity modulation, as well as better knowledge about possible age effects on neurovascular coupling. For instance, changes in factors such as cerebral blood flow, volume, and oxygen consumption may influence this relationship. Different mechanisms may also be active through different phases of life (D'Esposito et al., 2003). Nevertheless, the E/R flip was also related to source memory performance across the sample when controlling for age, indicating that modulation of activ- 
ity in this region is relevant for the ability to form and retrieve episodic memories.

\section{PMC as a network hub}

The age-related functional differences in the PMC might be related to its communication with other regions and networks, not just local properties of the region. The PMC shows connectivity with DMN nodes (Cauda et al., 2010), but also to other intrinsically connected networks, including task-positive frontoparietal networks that show the opposite activity patterns to the DMN (Fox et al., 2005). The PMC has wide structural connections (Hagmann et al., 2008) and the resting-state connectivity has been shown to correspond with structural connectivity measured by DTI (Greicius et al., 2009; Gordon et al., 2011; Horn et al., 2014). Assuming that PMC flexibility during encoding and retrieval is related to network interactions with other DMN nodes, we hypothesized that WM microstructure would relate to E/R flip and source memory performance. Although we found a significant interaction between source memory and age on the structural connectivity measures (MD) in left superior longitudinal fasciculus and left temporal lobe region, $\mathrm{MD}$ in this region was related to retrieval activity and E/R flip on a trend level only ( $p \sim$ $0.10)$ and not to source memory.

Multimodal imaging model of episodic memory development CT contributed indirectly to source memory performance through the E/R flip and CT was heavily influenced by age. Consistent with prior reports that consistently show maturation of CT as thinning of the cortex (Brown and Jernigan, 2012; Mutlu et al., 2013; Nguyen et al., 2013; Burgaleta et al., 2014; Wierenga et al., 2014b; Zielinski et al., 2014), we evinced reduction in CT with advanced age. Therefore, in addition to age, both CT in a sensory region associated with the memory task and modulation of activity in the PMC accounted for parts of the variance in source memory attributed to age. The source memory-thickness correlation in early visual cortices was significantly larger in young participants than in older participants. Retrieval of episodic components depends on reactivation of respective sensory regions that were active during encoding (Nyberg et al., 2000). The memory task presumably involved mental imagery and the interaction of age and source memory performance may reflect maturation of cortical regions needed for successful encoding and retrieval of visual episodic memories.

$\mathrm{E} / \mathrm{R}$ flip, $\mathrm{MD}$, and $\mathrm{CT}$ shared some age-related variance in source memory, but only E/R flip and CT explained unique parts of the variance: $8.1 \%$ and $28.9 \%$, respectively. Decomposing the $\mathrm{E} / \mathrm{R}$ flip into encoding and retrieval activity showed that modulation of activity between encoding and retrieval may provide a unique contribution to explain the age-source memory development, more so than the separate measures alone. In similar analyses in an aging sample, Hedden et al. (2016) also reported absence of unique contributions from DTI to age-related variance in episodic memory. Instead of using a priori defined global brain measures used by Hedden et al. (2016), we used measures tailored to the study; that is, extracted from regions where the relationship with source memory changed with age. Although we expected this to increase specificity to source memory for MD, we did not detect a significant relationship. However, the DTI data for the youngest children were collected in advance of the fMRI data, which may contribute as a limitation to the null findings. Nonetheless, when combined in the present study, neuroimaging measures explain a major part of episodic memory development in this age range.

\section{Limitations and future directions}

Although the sample size was 270 , only 21 children were aged 14 years or younger, which limits the precision in estimating age trajectories of the youngest part of the sample. Also, head motion is related to age and can potentially influence the results (Fig. 1) even if precautions are taken at several stages in the analyses. The study design is cross-sectional and the results represent age differences. Interpretation of brain-behavior relationships in periods of brain development may pose challenges, not least when structure and connectivity is considered in addition to brain activity alone (McCormick et al., 2017). The participants in the study were healthy and cognitively fit. Selection bias (e.g., withdrawal and survivor bias) and the cross-sectional design may have led to underestimation of the decline with age, particularly in older parts of the sample (Nyberg et al., 2010). A longitudinal replication attempt would be highly useful to estimate the size of cohort effects and other limitations of the study design.

The method for defining E/R flip resulted in small ROIs located on the edge of DMN nodes and the parietal memory network. These are neuroanatomically and functionally distinct regions and both anatomical variations and differences in parameters used for defining the ROIs may affect the overlap between ROIs and networks with possibly opposing activity patterns. Worth noting is that the E/R flip possibly occurs on border regions between functionally distinct networks and the behavior reflected as E/R flip may represent interaction or integration of activity in anatomically adjacent networks.

Future studies should aim to decompose the E/R flip further to gain a better understanding of the $\mathrm{E} / \mathrm{R}$ flip function in relation to functional and structural brain networks.

\section{Conclusion}

The present results show that preadolescent children show less modulation of neural activity in the PMC during encoding and retrieval operations. The E/R flip does not reach its peak until adolescence and decreases from adulthood through old age. The increase in the dynamic modulation of PMC activity appeared to continue into adulthood and then declined monotonously. Ultimately, between 70 and 80 years of age, a child-like pattern of PMC modulation was observed. A multimodal model could account for more than half of the age-related improvements in episodic memory performance in children and adolescents. These findings suggest a role of the PMC in both the emergence and decline of episodic memory.

\section{References}

Amlien IK, Fjell AM, Tamnes CK, Grydeland H, Krogsrud SK, Chaplin TA, Rosa MGP, Walhovd KB (2016) Organizing principles of human cortical development-thickness and area from 4 to 30 years: insights from comparative primate neuroanatomy. Cereb Cortex 26:257-267. CrossRef Medline

Andersson JLR, Jenkinson M (2007) Non-linear optimisation. FMRIB Technical Report TR07JA1. Available at: http://fsl.fmrib.ox.ac.uk/analysis/ techrep/tr07ja1/tr07ja1.pdf. Accessed December 12, 2016.

Andersson JLR, Sotiropoulos SN (2016) An integrated approach to correction for off-resonance effects and subject movement in diffusion MR imaging. Neuroimage 125:1063-1078. CrossRef Medline

Andersson JL, Skare S, Ashburner J (2003) How to correct susceptibility distortions in spin-echo echo-planar images: application to diffusion tensor imaging. Neuroimage 20:870-888. CrossRef Medline

Andersson JLR, Jenkinson M, Smith S (2007) Non-linear registration, aka Spatial normalisation FMRIB Technical Report TR07JA2. Available at: https:/www.fmrib.ox.ac.uk/analysis/techrep/tr07ja2/tr07ja2.pdf. Accessed December 12, 2016.

Beckmann CF, Smith SM (2004) Probabilistic independent component 
analysis for functional magnetic resonance imaging. IEEE Trans Med Imaging 23:137-152. CrossRef Medline

Blüml S, Wisnowski JL, Nelson MD Jr, Paquette L, Gilles FH, Kinney HC, Panigrahy A (2013) Metabolic maturation of the human brain from birth through adolescence: insights from in vivo magnetic resonance spectroscopy. Cereb Cortex 23:2944-2955. CrossRef Medline

Brown TT, Jernigan TL (2012) Brain development during the preschool years. Neuropsychol Rev 22:313-333. CrossRef Medline

Browne MW, Cudeck R (1992) Alternative ways of assessing model fit. Sociological Methods and Research 21:230-258. CrossRef

Buckner RL, Head D, Parker J, Fotenos AF, Marcus D, Morris JC, Snyder AZ (2004) A unified approach for morphometric and functional data analysis in young, old, and demented adults using automated atlas-based head size normalization: reliability and validation against manual measurement of total intracranial volume. Neuroimage 23:724-738. CrossRef Medline

Buckner RL, Andrews-Hanna JR, Schacter DL (2008) The brain's default network: anatomy, function, and relevance to disease. Ann N Y Acad Sci 1124:1-38. CrossRef Medline

Burgaleta M, Johnson W, Waber DP, Colom R, Karama S (2014) Cognitive ability changes and dynamics of cortical thickness development in healthy children and adolescents. Neuroimage 84:810-819. CrossRef Medline

Cauda F, Geminiani G, D'Agata F, Sacco K, Duca S, Bagshaw AP, Cavanna AE (2010) Functional connectivity of the posteromedial cortex. PLoS One 5:e13107. CrossRef Medline

Chai XJ, Ofen N, Gabrieli JD, Whitfield-Gabrieli S (2014) Development of deactivation of the default-mode network during episodic memory formation. Neuroimage 84:932-938. CrossRef Medline

Dale AM, Fischl B, Sereno MI (1999) Cortical surface-based analysis. I. Segmentation and surface reconstruction. Neuroimage 9:179-194. CrossRef Medline

Daselaar SM, Prince SE, Cabeza R (2004) When less means more: deactivations during encoding that predict subsequent memory. Neuroimage 23: 921-927. CrossRef Medline

Daselaar SM, Prince SE, Dennis NA, Hayes SM, Kim H, Cabeza R (2009a) Posterior midline and ventral parietal activity is associated with retrieval success and encoding failure. Front Hum Neurosci 3:13. CrossRef Medline

Daselaar SM, Prince SE, Dennis NA, Hayes SM, Kim H, Cabeza R (2009b) Posterior midline and ventral parietal activity is associated with retrieval success and encoding failure. Front Hum Neurosci 3:13. CrossRef

Degnan AJ, Ceschin R, Lee V, Schmithorst VJ, Blüml S, Panigrahy A (2014) Early metabolic development of posteromedial cortex and thalamus in humans analyzed via in vivo quantitative magnetic resonance spectroscopy. J Comp Neurol 522:3717-3732. CrossRef Medline

Desikan RS, Ségonne F, Fischl B, Quinn BT, Dickerson BC, Blacker D, Buckner RL, Dale AM, Maguire RP, Hyman BT, Albert MS, Killiany RJ (2006) An automated labeling system for subdividing the human cerebral cortex on MRI scans into gyral based regions of interest. Neuroimage 31:968980. CrossRef Medline

D'Esposito M, Deouell LY, Gazzaley A (2003) Alterations in the bold FMRI signal with ageing and disease: a challenge for neuroimaging. Nat Rev Neurosci 4:863-872. CrossRef Medline

Duarte A, Graham KS, Henson RN (2010) Age-related changes in neural activity associated with familiarity, recollection and false recognition. Neurobiol Aging 31:1814-1830. CrossRef Medline

Fischl B, Salat DH, Busa E, Albert M, Dieterich M, Haselgrove C, van der Kouwe A, Killiany R, Kennedy D, Klaveness S, Montillo A, Makris N, Rosen B, Dale AM (2002) Whole brain segmentation: automated labeling of neuroanatomical structures in the human brain. Neuron 33:341355. CrossRef Medline

Fischl B, Salat DH, van der Kouwe AJ, Makris N, Ségonne F, Quinn BT, Dale AM (2004a) Sequence-independent segmentation of magnetic resonance images. Neuroimage 23:S69-S84. CrossRef Medline

Fischl B, van der Kouwe A, Destrieux C, Halgren E, Ségonne F, Salat DH, Busa E, Seidman LJ, Goldstein J, Kennedy D, Caviness V, Makris N, Rosen B, Dale AM (2004b) Automatically parcellating the human cerebral cortex. Cereb Cortex 14:11-22. CrossRef Medline

Fjell AM, Westlye LT, Espeseth T, Reinvang I, Raz N, Agartz I, Salat DH, Greve DN, Fischl B, Dale AM, Walhovd KB (2009) Minute effects of sex on the aging brain: a multisample magnetic resonance imaging study of healthy aging and Alzheimer's disease. J Neurosci 29:8774-8783.
Fox MD, Snyder AZ, Vincent JL, Corbetta M, Van Essen DC, Raichle ME (2005) The human brain is intrinsically organized into dynamic, anticorrelated functional networks. Proc Natl Acad Sci U S A 102:9673-9678. CrossRef Medline

Gao W, Zhu H, Giovanello KS, Smith JK, Shen D, Gilmore JH, Lin W (2009) Evidence on the emergence of the brain's default network from 2-weekold to 2-year-old healthy pediatric subjects. Proc Natl Acad Sci U S A 106:6790-6795. CrossRef Medline

Ghetti S, Bunge SA (2012) Neural changes underlying the development of episodic memory during middle childhood. Developmental Cognitive Neuroscience 2:381-395. CrossRef Medline

Gilmore AW, Nelson SM, McDermott KB (2015) A parietal memory network revealed by multiple MRI methods. Trends Cogn Sci 19:534-543. CrossRef Medline

Gordon EM, Lee PS, Maisog JM, Foss-Feig J, Billington ME, Vanmeter J, Vaidya CJ (2011) Strength of default mode resting-state connectivity relates to white matter integrity in children. Dev Sci 14:738-751. CrossRef Medline

Greicius MD, Supekar K, Menon V, Dougherty RF (2009) Resting-state functional connectivity reflects structural connectivity in the default mode network. Cereb Cortex 19:72-78. CrossRef Medline

Griffanti L, Salimi-Khorshidi G, Beckmann CF, Auerbach EJ, Douaud G, Sexton CE, Zsoldos E, Ebmeier KP, Filippini N, Mackay CE, Moeller S, Xu J, Yacoub E, Baselli G, Ugurbil K, Miller KL, Smith SM (2014) ICAbased artefact removal and accelerated fMRI acquisition for improved resting state network imaging. Neuroimage 95:232-247. CrossRef Medline

Hagmann P, Cammoun L, Gigandet X, Meuli R, Honey CJ, Wedeen VJ, Sporns O (2008) Mapping the structural core of human cereb cortex. PLoS Biol 6:e159. CrossRef Medline

Hedden T, Schultz AP, Rieckmann A, Mormino EC, Johnson KA, Sperling RA, Buckner RL (2016) Multiple brain markers are linked to age-related variation in cognition. Cereb Cortex 26:1388-1400. CrossRef Medline

Hegarty CE, Foland-Ross LC, Narr KL, Townsend JD, Bookheimer SY, Thompson PM, Altshuler LL (2012) Anterior cingulate activation relates to local cortical thickness. Neuroreport 23:420-424. CrossRef Medline

Horn A, Ostwald D, Reisert M, Blankenburg F (2014) The structuralfunctional connectome and the default mode network of the human brain. Neuroimage 102:142-151. CrossRef Medline

Huijbers W, Vannini P, Sperling RA, C M P, Cabeza R, Daselaar SM (2012) Explaining the encoding/retrieval flip: memory-related deactivations and activations in the posteromedial cortex. Neuropsychologia 50:37643774. CrossRef Medline

Huijbers W, Schultz AP, Vannini P, McLaren DG, Wigman SE, Ward AM, Hedden T, Sperling RA (2013) The Encoding/Retrieval flip: interactions between memory performance and memory stage and relationship to intrinsic cortical networks. J Cogn Neurosci 25:1163-1179. CrossRef Medline

Inano S, Takao H, Hayashi N, Abe O, Ohtomo K (2011) Effects of age and gender on white matter integrity. Am J Neuroradiol 32:2103-2109. CrossRef Medline

Jenkinson M, Bannister P, Brady M, Smith S (2002) Improved optimization for the robust and accurate linear registration and motion correction of brain images. Neuroimage 17:825-841. CrossRef Medline

Joshi SH, Vizueta N, Foland-Ross L, Townsend JD, Bookheimer SY, Thompson PM, Narr KL, Altshuler LL (2016) Relationships between altered functional magnetic resonance imaging activation and cortical thickness in patients with euthymic bipolar I disorder. Biological Psychiatry: Cognitive Neuroscience and Neuroimaging 1:507-517. CrossRef

Kanaan RA, Allin M, Picchioni M, Barker GJ, Daly E, Shergill SS, Woolley J, McGuire PK (2012) Gender differences in white matter microstructure. PLoS One 7:e38272. CrossRef Medline

Kim H (2011) Neural activity that predicts subsequent memory and forgetting: a meta-analysis of $74 \mathrm{fMRI}$ studies. Neuroimage 54:2446-2461. CrossRef Medline

Kim H (2013) Differential neural activity in the recognition of old versus new events: an activation likelihood estimation meta-analysis. Hum Brain Mapp 34:814-836. CrossRef Medline

Kim H, Daselaar SM, Cabeza R (2010) Overlapping brain activity between episodic memory encoding and retrieval: roles of the task-positive and task-negative networks. Neuroimage 49:1045-1054. CrossRef Medline 
Leemans A, Jones DK (2009) The B-matrix must be rotated when correcting for subject motion in DTI data. Magn Reson Med 61:1336-1349. CrossRef Medline

Lundstrom BN, Petersson KM, Andersson J, Johansson M, Fransson P, Ing$\operatorname{var}$ M (2003) Isolating the retrieval of imagined pictures during episodic memory: activation of the left precuneus and left prefrontal cortex. Neuroimage 20:1934-1943. CrossRef Medline

McCormick EM, Qu Y, Telzer EH (2017) Activation in context: differential conclusions drawn from cross-sectional and longitudinal analyses of adolescents' cognitive control-related neural activity. Front Hum Neurosci 11:141. CrossRef Medline

Mutlu AK, Schneider M, Debbané M, Badoud D, Eliez S, Schaer M (2013) Sex differences in thickness, and folding developments throughout the cortex. Neuroimage 82:200-207. CrossRef Medline

Nguyen TV, McCracken J, Ducharme S, Botteron KN, Mahabir M, Johnson W, Israel M, Evans AC, Karama S; Brain Development Cooperative Group (2013) Testosterone-related cortical maturation across childhood and adolescence. Cereb Cortex 23:1424-1432. CrossRef Medline

Nichols T, Brett M, Andersson J, Wager T, Poline JB (2005) Valid conjunction inference with the minimum statistic. Neuroimage 25:653-660. CrossRef Medline

Nyberg L, Habib R, McIntosh AR, Tulving E (2000) Reactivation of encoding-related brain activity during memory retrieval. Proc Natl Acad Sci U S A 97:11120-11124. CrossRef Medline

Nyberg L, Salami A, Andersson M, Eriksson J, Kalpouzos G, Kauppi K, Lind J, Pudas S, Persson J, Nilsson LG (2010) Longitudinal evidence for diminished frontal cortex function in aging. Proc Natl Acad Sci U S A 107: 22682-22686. CrossRef Medline

Ofen N, Kao YC, Sokol-Hessner P, Kim H, Whitfield-Gabrieli S, Gabrieli JD (2007) Development of the declarative memory system in the human brain. Nat Neurosci 10:1198-1205. CrossRef Medline

Ollinger JM, Shulman GL, Corbetta M (2001) Separating processes within a trial in event-related functional MRI. Neuroimage 13:210-217. CrossRef Medline

Ostby Y, Tamnes CK, Fjell AM, Westlye LT, Due-Tønnessen P, Walhovd KB (2009) Heterogeneity in subcortical brain development: a structural magnetic resonance imaging study of brain maturation from 8 to 30 years. J Neurosci 29:11772-11782. CrossRef Medline

Otten LJ, Rugg MD (2001) Task-dependency of the neural correlates of episodic encoding as measured by fMRI. Cereb Cortex 11:1150-1160. CrossRef Medline

Power JD, Fair DA, Schlaggar BL, Petersen SE (2010) The development of human functional brain networks. Neuron 67:735-748. CrossRef Medline

Raichle ME, MacLeod AM, Snyder AZ, Powers WJ, Gusnard DA, Shulman GL (2001) A default mode of brain function. Proc Natl Acad Sci U S A 98:676-682. CrossRef Medline

Rasser PE, Johnston P, Lagopoulos J, Ward PB, Schall U, Thienel R, Bender S, Toga AW, Thompson PM (2005) Functional MRI BOLD response to tower of london performance of first-episode schizophrenia patients using cortical pattern matching. Neuroimage 26:941-951. CrossRef Medline

Rathee R, Rallabandi VP, Roy PK (2016) Age-related differences in white matter integrity in healthy human brain: evidence from structural MRI and diffusion tensor imaging. Magn Reson Insights 9:9-20. CrossRef Medline

Raznahan A, Shaw P, Lalonde F, Stockman M, Wallace GL, Greenstein D, Clasen L, Gogtay N, Giedd JN (2011) How does your cortex grow? J Neurosci 31:7174-7177.

Reuter M, Rosas HD, Fischl B (2010) Highly accurate inverse consistent registration: a robust approach. Neuroimage 53:1181-1196. CrossRef Medline

Rueckert D, Sonoda LI, Hayes C, Hill DL, Leach MO, Hawkes DJ (1999) Nonrigid registration using free-form deformations: application to breast MR images. IEEE Trans Med Imaging 18:712-721. CrossRef Medline

Salimi-Khorshidi G, Douaud G, Beckmann CF, Glasser MF, Griffanti L, Smith SM (2014) Automatic denoising of functional MRI data: combining independent component analysis and hierarchical fusion of classifiers. Neuroimage 90:449-468. CrossRef Medline

Schmidt MF, Storrs JM, Freeman KB, Jack CR Jr, Turner ST, Griswold ME, Mosley TH Jr (2018) A comparison of manual tracing and FreeSurfer for estimating hippocampal volume over the adult lifespan. Hum Brain Mapp 39:2500-2513. CrossRef Medline

Schoemaker D, Buss C, Head K, Sandman CA, Davis EP, Chakravarty MM, Gauthier S, Pruessner JC (2016) Hippocampus and amygdala volumes from magnetic resonance images in children: assessing accuracy of FreeSurfer and FSL against manual segmentation. Neuroimage 129:1-14. CrossRef Medline

Ségonne F, Dale AM, Busa E, Glessner M, Salat D, Hahn HK, Fischl B (2004) A hybrid approach to the skull stripping problem in MRI. Neuroimage 22:1060-1075. CrossRef Medline

Serences JT (2004) A comparison of methods for characterizing the eventrelated BOLD time series in rapid fMRI. Neuroimage 21:1690-1700. CrossRef Medline

Sled JG, Zijdenbos AP, Evans AC (1998) A nonparametric method for automatic correction of intensity nonuniformity in MRI data. IEEE Trans Med Imaging 17:87-97. CrossRef Medline

Smith SM (2002) Fast robust automated brain extraction. Hum Brain Mapp 17:143-155. CrossRef Medline

Smith SM, Nichols TE (2009) Threshold-free cluster enhancement: Addressing problems of smoothing, threshold dependence and localisation in cluster inference. Neuroimage 44:83-98.

Smith SM, Jenkinson M, Woolrich MW, Beckmann CF, Behrens TE, Johansen-Berg H, Bannister PR, De Luca M, Drobnjak I, Flitney DE, Niazy RK, Saunders J, Vickers J, Zhang Y, De Stefano N, Brady JM, Matthews PM (2004) Advances in functional and structural MR image analysis and implementation as FSL. Neuroimage 23:S208-S219. CrossRef Medline

Smith SM, Jenkinson M, Johansen-Berg H, Rueckert D, Nichols TE, Mackay CE, Watkins KE, Ciccarelli O, Cader MZ, Matthews PM, Behrens TE (2006) Tract-based spatial statistics: voxelwise analysis of multi-subject diffusion data. Neuroimage 31:1487-1505. CrossRef Medline

Sneve MH, Grydeland H, Nyberg L, Bowles B, Amlien IK, Langnes E, Walhovd KB, Fjell AM (2015) Mechanisms underlying encoding of shortlived versus durable episodic memories. J Neurosci 35:5202-5212. CrossRef Medline

Supekar K, Musen M, Menon V (2009) Development of large-scale functional brain networks in children. PLoS Biol 7:e1000157. CrossRef Medline

Tamnes CK, Ostby Y, Fjell AM, Westlye LT, Due-Tønnessen P, Walhovd KB (2010) Brain maturation in adolescence and young adulthood: regional age-related changes in cortical thickness and white matter volume and microstructure. Cereb Cortex 20:534-548. CrossRef Medline

Tamnes CK, Walhovd KB, Dale AM, Ostby Y, Grydeland H, Richardson G, Westlye LT, Roddey JC, Hagler DJ Jr, Due-Tønnessen P, Holland D, Fjell AM (2013) Brain development and aging: overlapping and unique patterns of change. Neuroimage 68:63-74. CrossRef Medline

Thirion B, Pinel P, Mériaux S, Roche A, Dehaene S, Poline JB (2007) Analysis of a large fMRI cohort: statistical and methodological issues for group analyses. Neuroimage 35:105-120. CrossRef Medline

Van Petten C (2004) Relationship between hippocampal volume and memory ability in healthy individuals across the lifespan: review and metaanalysis. Neuropsychologia 42:1394-1413. CrossRef Medline

Vannini P, O’Brien J, O'Keefe K, Pihlajamäki M, Laviolette P, Sperling RA (2011) What goes down must come up: role of the posteromedial cortices in encoding and retrieval. Cereb Cortex 21:22-34. CrossRef Medline

Vannini P, Hedden T, Huijbers W, Ward A, Johnson KA, Sperling RA (2013) The ups and downs of the posteromedial cortex: age- and amyloid-related functional alterations of the encoding/retrieval flip in cognitively normal older adults. Cereb Cortex 23:1317-1328. CrossRef Medline

Vidal-Piñeiro D, Sneve MH, Storsve AB, Roe JM, Walhovd KB, Fjell AM (2017) Neural correlates of durable memories across the adult lifespan: brain activity at encoding and retrieval. Neurobiol Aging 60:20-33. CrossRef Medline

Wagner AD, Davachi L (2001) Cognitive neuroscience: forgetting of things past. Curr Biol 11:R964-R967. CrossRef Medline

Wagner AD, Shannon BJ, Kahn I, Buckner RL (2005) Parietal lobe contributions to episodic memory retrieval. Trends Cogn Sci 9:445-453. CrossRef Medline

Walhovd KB, Westlye LT, Amlien I, Espeseth T, Reinvang I, Raz N, Agartz I, Salat DH, Greve DN, Fischl B, Dale AM, Fjell AM (2011) Consistent neuroanatomical age-related volume differences across multiple samples. Neurobiol Aging 32:916-932. CrossRef Medline 
Wenger E, Mårtensson J, Noack H, Bodammer NC, Kühn S, Schaefer S, Heinze HJ, Düzel E, Bäckman L, Lindenberger U, Lövdén M (2014) Comparing manual and automatic segmentation of hippocampal volumes: reliability and validity issues in younger and older brains. Hum Brain Mapp 35:4236-4248. CrossRef Medline

Wierenga L, Langen M, Ambrosino S, van Dijk S, Oranje B, Durston S (2014a) Typical development of basal ganglia, hippocampus, amygdala and cerebellum from age 7 to 24 . Neuroimage 96:67-72. CrossRef Medline

Wierenga LM, Langen M, Oranje B, Durston S (2014b) Unique developmental trajectories of cortical thickness and surface area. Neuroimage 87:120-126. CrossRef Medline
Winkler AM, Ridgway GR, Webster MA, Smith SM, Nichols TE (2014) Permutation inference for the general linear model. Neuroimage 92:381-397.

Wonderlick JS, Ziegler DA, Hosseini-Varnamkhasti P, Locascio JJ, Bakkour A, van der Kouwe A, Triantafyllou C, Corkin S, Dickerson BC (2009) Reliability of MRI-derived cortical and subcortical morphometric measures: effects of pulse sequence, voxel geometry, and parallel imaging. Neuroimage 44:1324-1333. CrossRef Medline

Zielinski BA, Prigge MB, Nielsen JA, Froehlich AL, Abildskov TJ, Anderson JS, Fletcher PT, Zygmunt KM, Travers BG, Lange N, Alexander AL, Bigler ED, Lainhart JE (2014) Longitudinal changes in cortical thickness in autism and typical development. Brain 137:1799-1812. CrossRef Medline 